\title{
Mixing in the Romanche Fracture Zone
}

\author{
Bruno Ferron, Herlé Mercier, and Kevin Speer \\ Laboratoire de Physique des Océans, Institut Français de Recherche pour l'Exploitation de la Mer, Brest, France
}

ANN GARGETT

Institute of Ocean Sciences, Sidney, British Columbia, Canada

KURT POLZIN

Woods Hole Oceanographic Institution, Woods Hole, Massachusetts

(Manuscript received 14 April 1997, in final form 11 December 1997)

\section{ABSTRACT}

\begin{abstract}
The Romanche Fracture Zone is a major gap in the Mid-Atlantic Ridge at the equator, which is deep enough to allow significant eastward flows of Antarctic Bottom Water from the Brazil Basin to the Sierra Leone and Guinea Abyssal Plains. While flowing through the Romanche Fracture Zone, bottom-water properties are strongly modified due to intense vertical mixing. The diapycnal mixing coefficient in the bottom water of the Romanche Fracture Zone is estimated by using the finestructure of CTD profiles, the microstructure of high-resolution profiler data, and by constructing a heat budget from current meter data.

The finestructure of density profiles is described using the Thorpe scales $L_{T}$. It is shown from microstructure data taken in the bottom water that the Ozmidov scale $L_{O}$ is related to $L_{T}$ by the linear relationship $L_{O}=0.95 L_{T}$, similar to other studies, which allows an estimate of the diapycnal mixing coefficient using the Osborn relation. The Thorpe scale and the diapycnal mixing coefficient estimates show enhanced mixing downstream (eastward) of the main sill of the Romanche Fracture Zone. In this region, a mean diapycnal mixing coefficient of about $1000 \times 10^{-4} \mathrm{~m}^{2} \mathrm{~s}^{-1}$ is found for the bottom water.

Estimates of cross-isothermal mixing coefficient derived from the heat budgets constructed downstream of the current meter arrays deployed in the Romanche Fracture Zone and the nearby Chain Fracture Zone are in agreement with the finestructure estimates of the diapycnal mixing coefficient within the Romanche Fracture Zone. Although the two fracture zones occupy only $0.4 \%$ of the area covered by the Sierra Leone and Guinea Abyssal Plains, the diffusive heat fluxes across the $1.4^{\circ} \mathrm{C}$ isotherm in the Romanche and Chain Fracture Zones are half that found over the abyssal plains across the $1.8^{\circ} \mathrm{C}$ isotherm, emphasizing the role of these passages for bottom-water property modifications.
\end{abstract}

\section{Introduction}

The densest water masses formed at high latitudes during cold winters spread into the equatorial Atlantic Ocean where they mix and upwell. The Lower North Atlantic Deep Water (LNADW), found around 3600$4000 \mathrm{~m}$, comes from the Norwegian-Greenland Seas and is marked by relatively high salinity, oxygen, and freon concentrations. The Antarctic Bottom Water (AABW), which lies below the LNADW down to the seafloor, originates around Antarctica and is characterized by low potential temperature and salinity and high silicate concentration. As the AABW flows away from its formation region, it is severely constrained by bathy-

Corresponding author address: Bruno Ferron, IFREMER, Laboratoire de Physique des Océans, B.P. 70, 29280 Plouzané, France. E-mail: bferron@ifremer.fr metric features such as ridges, valleys, or fracture zones. In the South Atlantic Ocean, the Walvis Ridge near $25^{\circ} \mathrm{S}$ prevents the northward spreading of the AABW in the eastern trough (Warren and Speer 1991). Hence, it is confined to the western basin, and interbasin exchanges can only occur through fracture zones in the Mid-Atlantic Ridge.

The Romanche Fracture Zone (RFZ), which crosses the equator, and the Chain Fracture Zone (CFZ), located near $1^{\circ} \mathrm{S}$ (Fig. 1), are pathways through the Mid-Atlantic Ridge for the LNADW and the AABW. The role of these two major transform faults is emphasized in Mantyla and Reid (1983, their Figs. 2b and 2c), who show a relatively cold and fresh tongue of AABW crossing the Mid-Atlantic Ridge at the equator. They also reveal an abrupt warming and salinification of AABW as it penetrates eastward toward the abyssal plains. In order to quantify the importance of these two passages for the deep and bottom water circulations and water mass 

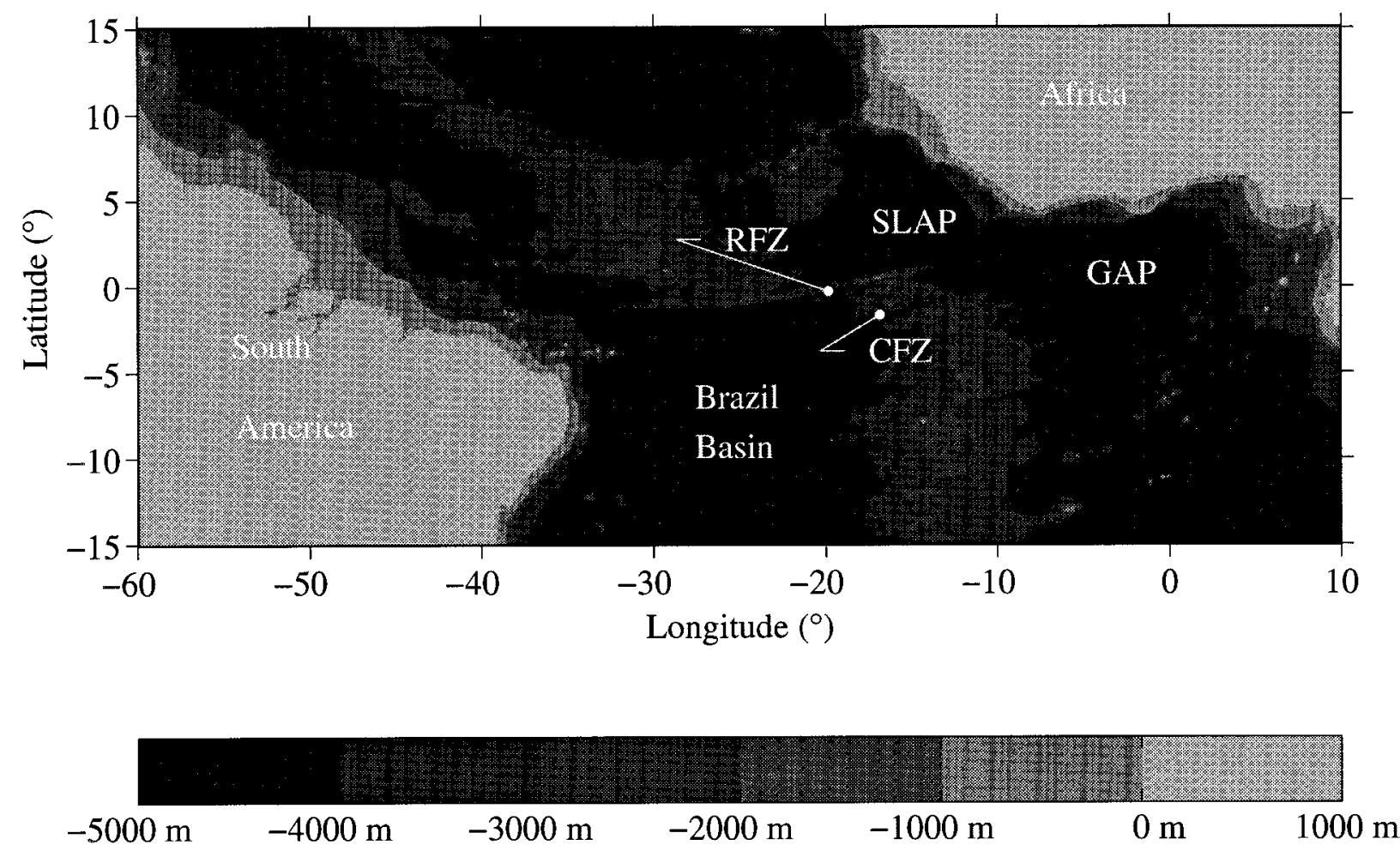

FIG. 1. Bathymetric map of the equatorial Atlantic Ocean from ETOPO5 Atlas. Locations of the Romanche Fracture Zone (RFZ), the Chain Fracture Zone (CFZ), the Sierra Leone Abyssal Plain (SLAP), and the Guinea Abyssal Plain (GAP) are indicated.

transformations, a series of cruises was organized as part of the Deep Basin Experiment (DBE) of the World Ocean Circulation Experiment (WOCE).

Hydrographic and multibeam echo sounder bathymetric data obtained on these cruises permitted the identification of the pathways for bottom water across the Mid-Atlantic Ridge at the equator and revealed large property changes of the AABW and LNADW during

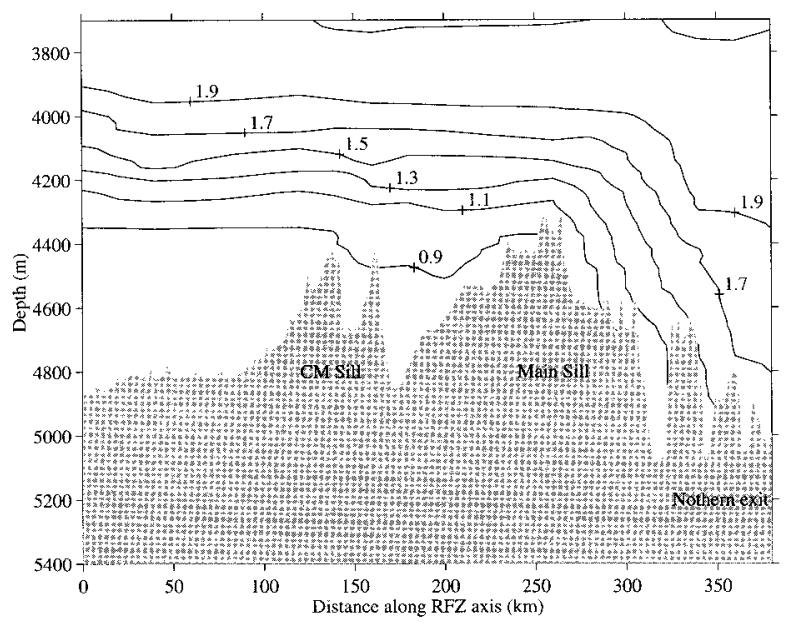

FIG. 2. Potential temperature $\left({ }^{\circ} \mathrm{C}\right)$ section along the RFZ valley (adapted from Mercier and Morin 1997). their eastward transit through the RFZ and CFZ (Mercier et al. 1994; Mercier and Morin 1997). The near-bottom potential temperature increases by $0.5^{\circ} \mathrm{C}$ over $250 \mathrm{~km}$ as the AABW flows eastward in the RFZ, from the current meter sill to the northern exit leading to the Sierra Leone Abyssal Plain (Fig. 2). Mercier et al. (1994) explained such a large warming by both the blocking of the densest AABW by the sills and by turbulent mixing occuring downstream of the main sill. To emphasize how intense the modifications of the AABW properties are in the RFZ, note that the AABW experiences a similar increase in bottom temperature in its $1500 \mathrm{~km}$ northward traverse of the Brazil Basin (Mantyla and Reid 1983). Mercier and Morin (1997) concluded that an intense vertical mixing $K_{\rho}$ could extend to $500 \mathrm{~m}$ above the bottom downstream of the main sill and was responsible for the modification of the AABW. Polzin et al. (1996) deduced a mean $K_{\rho}$ from microstructure data of $150 \times 10^{-4} \mathrm{~m}^{2} \mathrm{~s}^{-1}$ below $4000 \mathrm{~m}$ downstream of the main sill and identified strong bottom vertical shears as a possible source of turbulence as well as hydraulic jumps associated with hydraulic control.

In a thermodynamic steady state, closure of the thermohaline circulation is accomplished by vertical mixing and upwelling. The intensity of the mixing, its geographical distribution, and causal physical mechanisms have been subjects of much speculation. Recent direct estimates of turbulent dissipation suggest 1) vigorous 
mixing in close proximity to the rough bathymetry of midocean ridges, which is associated with internal wave breaking and supported by a locally enhanced internal wave field (Polzin et al. 1997), and 2) much more intense mixing associated with the instability of strongly sheared flows within constrained passages (Polzin et al. 1996). Since the vertical distribution of turbulent dissipation is directly related to the diapycnal velocity field through the diapycnal advection/diffusion balance, the distinction between these two mechanisms has important consequences for an enclosed basin.

This paper is organized as follows. Section 2 describes the dataset composed of conductivity-temperature-depth (CTD) profiles, high-resolution profiler (HRP, Schmitt et al. 1988) casts, and two-year-long current-temperature meter measurements taken in the RFZ and CFZ. Section 3 presents the length scale statistics, namely the Ozmidov scale (Ozmidov 1965) computed from the HRP data, and the Thorpe scale (Thorpe 1977) from the CTD and HRP casts documenting the intensity, the spatial structure, and the characteristics of the turbulence. It is shown that the largest Thorpe scales are found downstream of the main sill where the warming of the AABW is the largest. The relation between the Ozmidov scale and the Thorpe scale for our dataset is similar to previous studies. It has allowed us to estimate turbulent kinetic energy dissipation rates from finescale CTD and HRP profiles. This study emphasizes how CTD finescale vertical profiles may be used to study the finestructure and to infer microstructure information (dissipation). In section 4, we estimate the vertical mixing coefficient $K_{\rho}$ using two different approaches. First, we use the finestructure (Thorpe scales) of CTD profiles in order to calculate $K_{\rho}$ and its local vertical structure. The largest $K_{\rho}$ of order $1000 \times 10^{-4} \mathrm{~m}^{2} \mathrm{~s}^{-1}$ over a 1000-m layer depth are found at the exit of the RFZ. Then, integral mixing coefficients are inferred from a balance between current-temperature meter-derived advective heat fluxes and diffusive heat fluxes. Comparisons between the local and the integral estimates of the mixing show that diffusive heat fluxes are of the same order of magnitude in the known location of the mixing. The conclusion follows in section 5, and an appendix sets out the algorithm developed for the calculation of the Thorpe scales.

\section{The data}

A series of cruises in the equatorial fracture zones was made as part of the French Romanche programme, led by the Laboratoire de Physique des Océans (LPO), and of a companion project, Romanche Mélange (Romel), organized by the Woods Hole Oceanographic Institution and LPO. In August 1991, the Romanche 1 cruise (Mercier et al. 1992) explored the bathymetry and the hydrography of the RFZ and the CFZ. The results were a high-resolution bathymetric map (A. Bernard and H. Mercier 1996, personal communication) and a collection of CTD casts distributed over the RFZ and CFZ (Fig. 3). In November 1992 during the Romanche 2 cruise (Mercier et al. 1995), four current meter moorings were deployed in the RFZ and four in the CFZ in order to quantify the AABW transport through each passage. Two years later, in November 1994 during the Romanche 3 cruise (Mercier et al. 1997), the moorings were successfully recovered, and CTD casts reexplored some areas of the fracture zones. The Romel cruise occured three weeks after Romanche 3 . The focus was the vertical mixing within the fracture zones from CTD (tow-yos and yo-yos) and HRP stations that have been principally made at two locations (Fig. 3): the current meter mooring deployment region and the northern exit region. The Romanche 1 data suggested that strong mixing was occuring at the northern exit region. During Romanche 1, the CTD casts were made using a Neil Brown MKIII CTD operating at $32 \mathrm{~Hz}$. During Romanche 3 and Romel, a Seabird Sealogger CTD (8-Hz sampling rate) was used. Moorings were equipped with RCM5 and RCM8 Aanderaa temperature and current meters.

\section{The finestructure and microstructure of CTD data}

Two length scales are often used to study the finestructure (i.e., structures of the order of $1 \mathrm{~m}$ ) and microstructure (i.e., structures of the order of $1 \mathrm{~cm}$ ) of oceanic and atmospheric data.

The first is the Ozmidov scale $\left(L_{O}\right)$ (Ozmidov 1965):

$$
L_{O}=\epsilon^{1 / 2} N^{-3 / 2},
$$

where $\epsilon$ is the dissipation rate of turbulent kinetic energy, or the rate of energy transfer from large (finestructure) scales to small (microstructure) scales, and $N$ is the Brunt-Väisälä or buoyancy frequency. From an energetic point of view, $L_{O}$ corresponds, in a statistical mean, to the vertical distance $l$ a parcel of fluid will move if it converts all its kinetic energy (proportional to the square of the turbulent vertical velocity, $w^{2}$ ) into potential energy (proportional to $N^{2} l^{2}$ ). (This can be easily shown, remembering that $\epsilon$ is proportional to $w^{3} / l$, e.g., Gargett 1994). Thus, $L_{O}$ is the maximum overturning length scale permitted in a stratified fluid.

The second scale is the Thorpe scale $L_{T}$ (Thorpe 1977): $L_{T}$ is a measure of the vertical length scale of density inversions that, in a stratified fluid, are associated with gravitational instabilities.

In order to estimate $L_{T}$ from data taken in freshwater, Thorpe (1977) proposed to order adiabatically a vertical profile of temperature containing small temperature inversions in order to construct a stable profile (i.e., one in which there is no available potential energy). The difference in positions of each fluid parcel between the initial and the ordered profiles gives nonzero displacements where instabilities exist in the measured profile. The Thorpe scale is then calculated as the root-mean- 

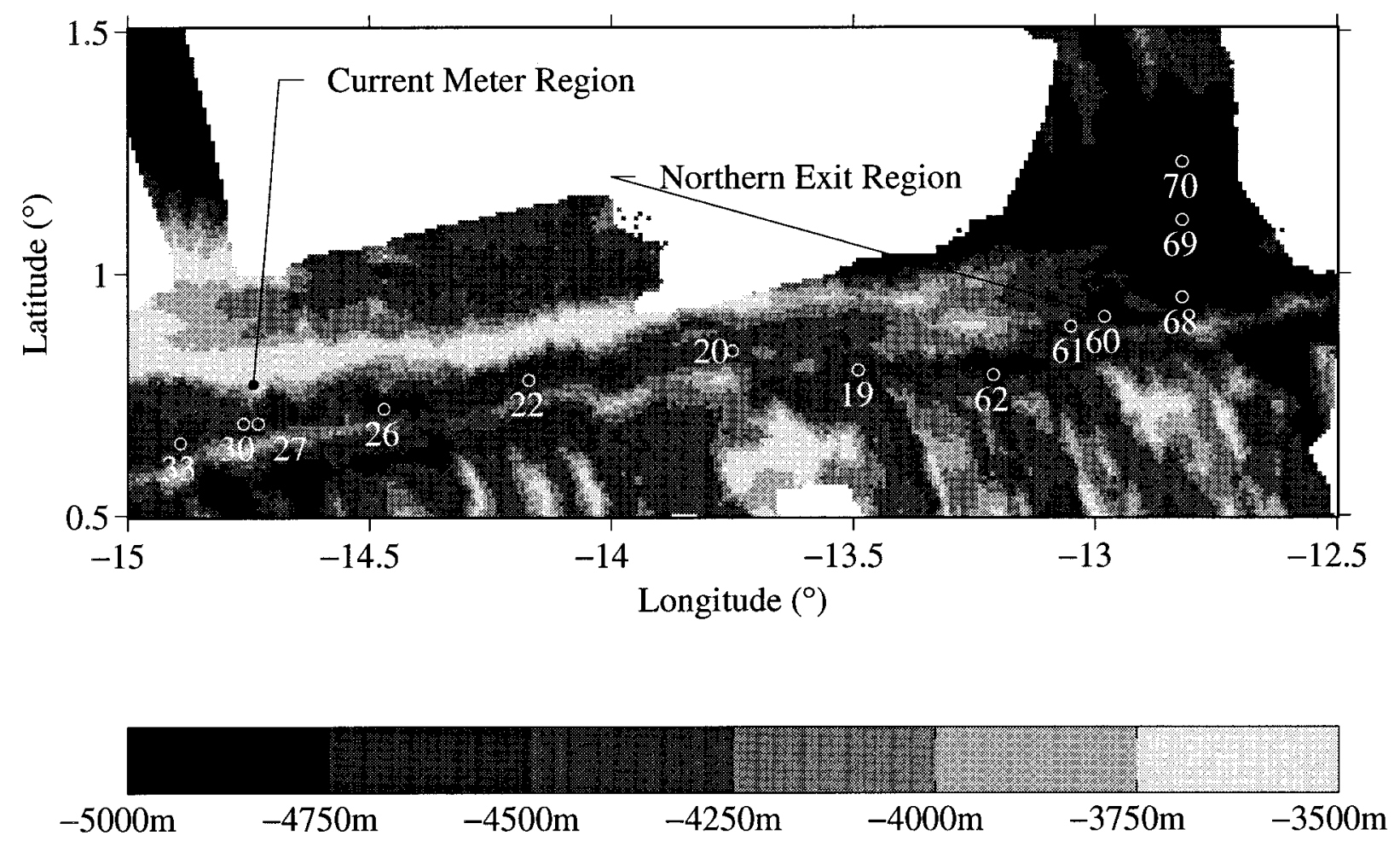

FIG. 3. High-resolution bathymetric map of the RFZ from multibeam sounder (Mercier et al. 1994). Selected CTD stations occupied during Romanche 1 are indicated $(\bigcirc)$ as well as the two regions of intense CTD sampling during the Romel expedition. The main sill of the RFZ, near $4350 \mathrm{~m}$, is located at station 20 .

square (rms) value of the displacements for each unstable structure. That is, to each turbulent patch corresponds a typical constant displacement (positive definite as a consequence of the use of the rms), that is characteristic of the overturn vertical length scale.

In the next section, we present estimates of the Thorpe scales obtained from the CTD data. In addition, we use the HRP data to show that, for the bottom water, $L_{T}$ is linearly related to $L_{O}$.

\section{a. Statistical estimates of Thorpe scales}

The appendix details the algorithm used for estimating $L_{T}$ and compares the result it gives to other methods. The method takes into account the instrumental noise that contaminates the measurements, an important consideration when stratification is weak. The Thorpe scale that can be resolved depends on the sampling rate and noise level of the instrument. In our case, we use CTD data that were previously filtered and subsampled to 1 dbar to attenuate high-frequency noise. Hence, we cannot hope to resolve gravitational overturns smaller than 2 dbar or Thorpe scales $L_{T}$ less than $L_{T \text { min }}=1$ dbar. As we are sampling a region of strong mixing, this instrumental limitation is of no consequence for the data interpretation. The use of a CTD probe was sufficient to resolve the main instabilities, but note that $L_{T}=0$ does not necessarily imply that there is no overturn, but that we do not have a sufficient resolution to infer the existence of an overturn.

During the Romel experiment, CTD casts were done extensively in two regions: The first one falls between the current meter sill and the first adjoining downstream basin and will be referred to as the current meter region; this region extends from station 30 to station 27 in Fig. 3 . The second region, referred to as the northern exit region, begins at the seamount following station 61 and extends down to the adjacent basin where station 60 is located (Fig. 3). At the current meter region, a total of 22 CTD profiles, either down- or upcasts, were used for the Thorpe-scale calculation, whereas 34 profiles were used at the northern exit region. The Thorpe scales were computed for each station both from temperature and density profiles. This was done in order to compare both approaches, with the hope of validating calculations made with temperature. For each region, individual Thorpe scale profiles were averaged as a function of temperature (density) when the Thorpe scale calculation is based on temperature (density) profiles (Figs. 4 and $5)$. Note that the averaging process can result in averaged Thorpe scales smaller than $L_{T \min }$. This averaging method removes the effect produced by vertical advection downstream of a sill, which tends to spread and lower the intensity of Thorpe scales when depth or pressure averaging is taken. This same effect produced by the internal waves is also avoided. 

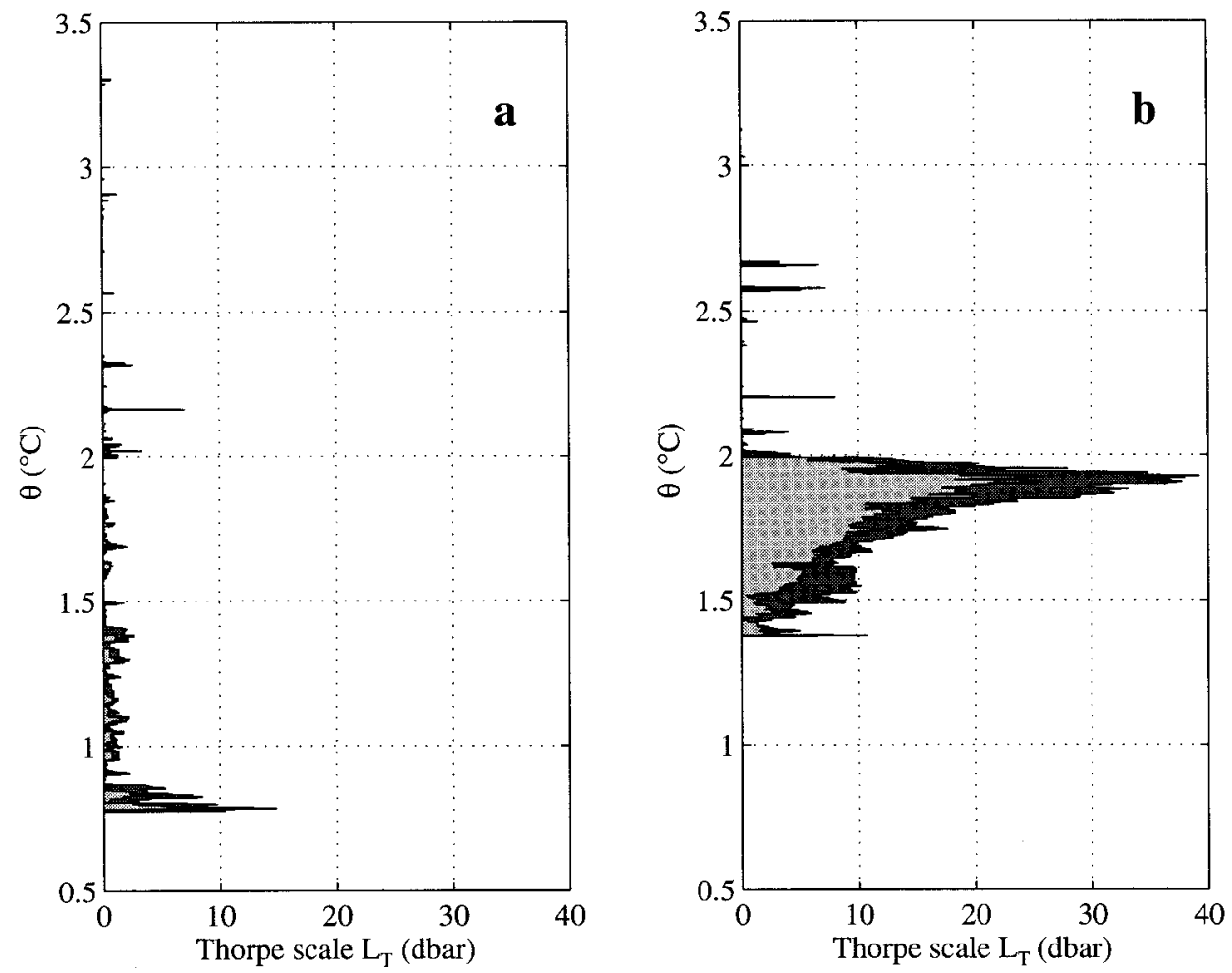

FIG. 4. (a) Thorpe scales (dbar) at the current meter region obtained as an average over 22 casts presented as a function of temperature. (b) Thorpe scale (dbar) at the northern exit region obtained as an average over 34 casts presented as a function of temperature. Dark gray is associated with the minimum noise $\delta=$ $0.001^{\circ} \mathrm{C}$, while light gray curve corresponds with four times this noise. Casts were collected during the Romel expedition.

As the calculated Thorpe scales might be sensitive to the choice of the instrumental noise level (see appendix for the definition of the noise), we show the results obtained for the current meter and northern exit regions using a noise of $0.001^{\circ} \mathrm{C}$ in temperature (dark gray, Fig. 4) and of $0.001 \mathrm{~kg} \mathrm{~m}^{-3}$ in density (dark gray, Fig. 5) as well as using four times these values (light gray, Figs. 4 and 5). The noise level for temperature was chosen according to specifications given by SEABIRD Inc. (1995, personal communication). Noise in density is dominated by the noise of the conductivity cell (a $\delta T$ $=10^{-3}{ }^{\circ} \mathrm{C}$ is, in terms of density, equal to a $\delta \rho=2 \times$ $10^{-4} \mathrm{~kg} \mathrm{~m}^{-3}$ for bottom waters), and $0.001 \mathrm{~kg} \mathrm{~m}^{-3}$ is a lower bound (A. Billant 1995, personal communication). Thorpe scales are also presented by temperature and density classes in Table 1.

Thorpe scales were also calculated from six HRP temperature profiles taken at the northern exit with a noise of $0.001{ }^{\circ} \mathrm{C}$ (Fig. 6). The HRP profiles are few and were not taken exactly at the same location as the CTD profiles used in Figs. 4 and 5. However, Thorpe scales calculated from HRP and CTD data (i.e., from two different sensors) are similar, which indicates that our choice of the temperature noise is reasonable.

Vertical profiles of $L_{T}$ indicate near statically stable conditions at the current meter sill (Fig. 4a) for tem- peratures from $3.5^{\circ}$ to $1.9^{\circ} \mathrm{C}$. The averaged Thorpe scale over this range of temperature is $0.07 \mathrm{dbar}$ for the lowest noise level (Table 1). Between $1.9^{\circ}$ and $0.9^{\circ} \mathrm{C}$, overturns are slightly more numerous and intense. The mean value of $L_{T}$ over the layer is $0.6 \mathrm{dbar}$. The layer whose temperature is colder than $0.9^{\circ} \mathrm{C}$ is more turbulent. Here, the Thorpe scale is $4.3 \mathrm{dbar}$. The results obtained for the northern exit region are dramatically different except for the $3.4^{\circ}-2^{\circ} \mathrm{C}$ temperature class, which also presents weak Thorpe scales (Fig. $4 \mathrm{~b}$ and Table 1). The striking feature is that turbulence now affects a broad band of temperatures corresponding with a layer depth of 1000 $\mathrm{m}$. The boundary between relatively quiet and turbulent fluid is quite well defined at $2^{\circ} \mathrm{C}$. Thorpe scales below this boundary are large. The largest Thorpe scales are no longer found near the bottom but are located at $\theta=$ $1.9^{\circ} \mathrm{C}$. For the $2^{\circ}-1.7^{\circ} \mathrm{C}$ temperature class, an averaged Thorpe scale of about $21 \mathrm{dbar}$ for the lowest noise level is found, while the averaged Thorpe scale is $7 \mathrm{dbar}$ for water colder than $1.7^{\circ} \mathrm{C}$.

Thorpe scales are also displayed as a function of density for the current meter sill and the northern exit region (Figs. 5a and 5b, Table 1). Calculating the Thorpe scale with density or temperature gives similar results for our set of data, which means that fluctuations of density are mainly driven by temperature at the observed scales. 

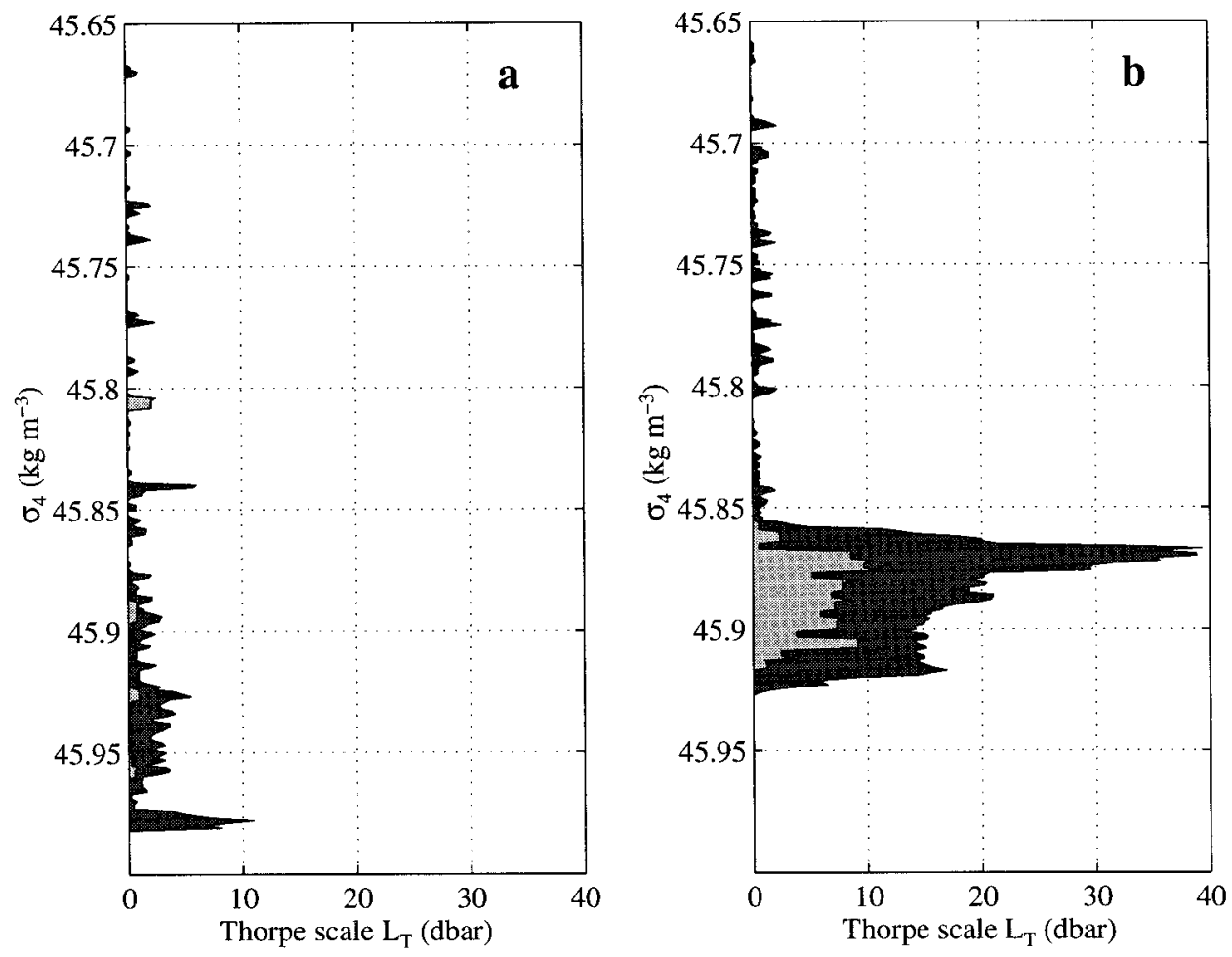

FIG. 5. Same as Fig. 4 but Thorpe scales were calculated with density and are presented as a function of density. Dark gray is associated with the minimum noise $\delta=0.001 \mathrm{~kg} \mathrm{~m}^{-3}$, while light gray curve corresponds with four times this noise. (a) Current meter region and (b) northern exit region.

TABLE 1. Thorpe scale by density and temperature layers for the current meter region and the northern exit. Twenty-two casts were used at the current meter region and 34 at the northern exit. The noise level $\delta$ taken on density is $0.001 \mathrm{~kg} \mathrm{~m}^{-3}$, whereas it is $0.001^{\circ} \mathrm{C}$ for the temperature.

\begin{tabular}{|c|c|c|c|c|}
\hline Parameter & $\begin{array}{l}\text { Geographic } \\
\text { region }\end{array}$ & $\begin{array}{c}\text { Layer } \\
\left(\mathrm{kg} \mathrm{m}^{-3} \text { or }{ }^{\circ} \mathrm{C}\right)\end{array}$ & Noise level & $L_{T}(\mathrm{dbar})$ \\
\hline \multirow[t]{4}{*}{ Density } & Current meter & $45.65 \leq \sigma_{4} \leq 45.875$ & $\begin{array}{l}\delta \\
4 \delta\end{array}$ & $\begin{array}{l}0.15 \\
0.04\end{array}$ \\
\hline & & $\begin{array}{c}45.875 \leq \sigma_{4} \leq 45.97 \\
\sigma_{4} \geq 45.97\end{array}$ & $\begin{array}{l}\delta \\
4 \delta \\
\delta \\
4 \delta\end{array}$ & $\begin{array}{l}1.6 \\
0.15 \\
3.67 \\
0\end{array}$ \\
\hline & Northern exit & $45.65 \leq \sigma_{4} \leq 45.86$ & $\begin{array}{l}\delta \\
4 \delta\end{array}$ & $\begin{array}{l}0.37 \\
0.01\end{array}$ \\
\hline & & $\begin{array}{c}45.86 \leq \sigma_{4} \leq 45.9 \\
\sigma_{4} \geq 45.9\end{array}$ & $\begin{array}{l}\delta \\
4 \delta \\
\delta \\
4 \delta\end{array}$ & $\begin{array}{l}21 \\
6.2 \\
12 \\
2.7\end{array}$ \\
\hline \multirow[t]{5}{*}{ Temperature } & Current meter & $1.9 \leq \theta \leq 3.4$ & $\begin{array}{l}\delta \\
4 \delta\end{array}$ & $\begin{array}{l}0.07 \\
0.01\end{array}$ \\
\hline & & $\begin{array}{c}0.9 \leq \theta \leq 1.9 \\
\theta \leq 0.9\end{array}$ & $\begin{array}{l}\delta \\
4 \delta \\
\delta \\
4 \delta\end{array}$ & $\begin{array}{l}0.62 \\
0.26 \\
4.3 \\
1.6\end{array}$ \\
\hline & Northern exit & $2.0 \leq \theta \leq 3.4$ & $\begin{array}{l}\delta \\
4 \delta\end{array}$ & $\begin{array}{l}0.14 \\
0.01\end{array}$ \\
\hline & & $1.7 \leq \theta \leq 2.0$ & $\delta$ & 21.4 \\
\hline & & $\theta \leq 1.7$ & $\begin{array}{l}4 \delta \\
\delta \\
4 \delta\end{array}$ & $\begin{array}{l}13 \\
7.4 \\
3.7\end{array}$ \\
\hline
\end{tabular}




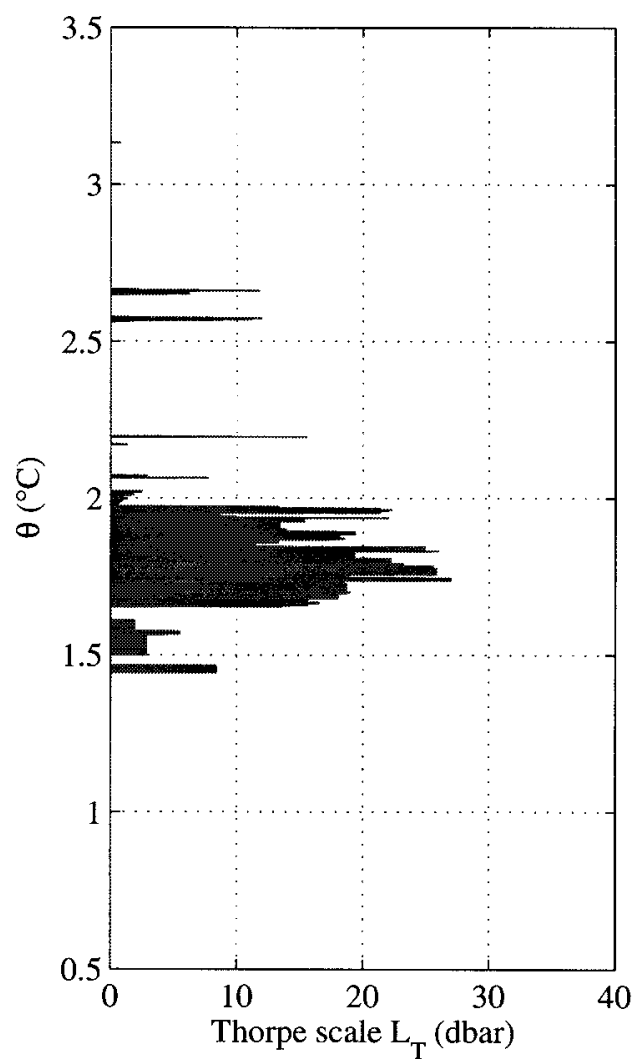

FIG. 6. Thorpe scales (dbar) averaged from six HRP temperature profiles taken at the northern exit. The noise is $0.001^{\circ} \mathrm{C}$ (cf. Fig. 4).

Nevertheless, Thorpe scales calculated with density are more sensitive to the choice of the noise level than Thorpe scales calculated with temperature. Indeed, multiplying the noise level by 4 causes a greater decrease in Thorpe scales calculated with density than those calculated with temperature (Table 1). When the noise is multiplied by 4 , only the largest inversions can be resolved. This means that the signal to noise ratio is better for temperature than for density, and it is the reason why Thorpe scales are usually calculated with temperature.

The $L_{T}$ computed from an average of eight repeated profiles taken at the northern exit region during the Romanche 3 cruise (Fig. 7), three weeks before the Romel cruise, exhibits the same characteristics as those of Figs. $4 \mathrm{~b}$ and $5 \mathrm{~b}$. The primary difference is that the maximum Thorpe scales are larger and occur at slightly lower temperatures for Romanche 3. The difference is most likely due to spatial and temporal variability. One can, however, conclude that, at the northern exit region, strong vertical mixing affects the properties of the deep water $1000 \mathrm{~m}$ above the bottom.

As the Thorpe scales calculated with temperature are close to those calculated with density and are less sensitive to the choice of the instrumental noise level, we decided to restrict the following discussions to Thorpe scales calculated with temperature.

\section{b. Thorpe scales along the RFZ valley}

Figure 8 shows the evolution of the Thorpe scales along the Romanche Fracture Zone valley. Each $L_{T}$ profile comes from one temperature profile of the Romanche 1 cruise. Weak overturns are found at station 33. Larger overturns are found at stations 30 to 26 between 3000 and $3500 \mathrm{~m}$. This upper overturning layer, though not clearly present at station 22 , exists from the main sill to the northern exit (stations 20 to 68). This layer is similarly encountered in Romanche 3 and also to a lesser extent in the Romel data. However, for these two last cruises, we do not have as extensive spatial coverage as in Romanche 1.

Near the bottom, large overturns are found downstream of sills in the valleys, whereas upstream of sills overturns are rather weak. The same remark can be made for the other casts of Romanche 1 , as well as for the three other cruises. Figure 8 highlights two regions of strong bottom overturning. The first lies in the basin immediately west of the main sill, near kilometer 60 . The second is at the succession of basins at the northern exit. Station 60 shows the strongest overturns. Not only are the overturns intense but they also extend well above the bottom. This contrasts with the other casts, where overturns were confined to the bottom and did not extend very far upward. The simple picture that may be derived from these observations is that dense fluid, initially forced by the zonal baroclinic pressure gradient, accelerates under buoyancy forces while spilling down into the valleys. This acceleration gives rise to the strong vertical shears observed by Polzin et al. (1996), which are a source of instability and turbulence.

Except in the upper (3000-3500 m) and bottom overturning regions, the overturns are seldom seen and not intense. This is in agreement with the classical view of intermittent turbulence in the interior of the ocean. From Figs. 2 and 8 we see that the intense warming of the bottom water occuring after the main sill is associated with large overturns. However, although Fig. 8 gives an overview of the turbulent regions in the RFZ, it does not allow quantification of the mixing, which requires stable statistics based on a large amount of data.

Qualitative agreement is found between this overview based on single profiles and the averaged Thorpe scales calculated from casts done three years later (Fig. 4). Station 27, from the current meter region, exhibits bottom-intensified turbulence, while station 60, located in the northern exit region shows large Thorpe scales far from the bottom. Hence, all the evidence gathered over several years points to stationary patterns.

\section{c. Determining the linear relationship between $L_{T}$ and $L_{O}$}

As noted earlier, the Ozmidov scale $L_{O}=\epsilon^{1 / 2} N^{-3 / 2}$ is another estimate of the overturning length. In order 

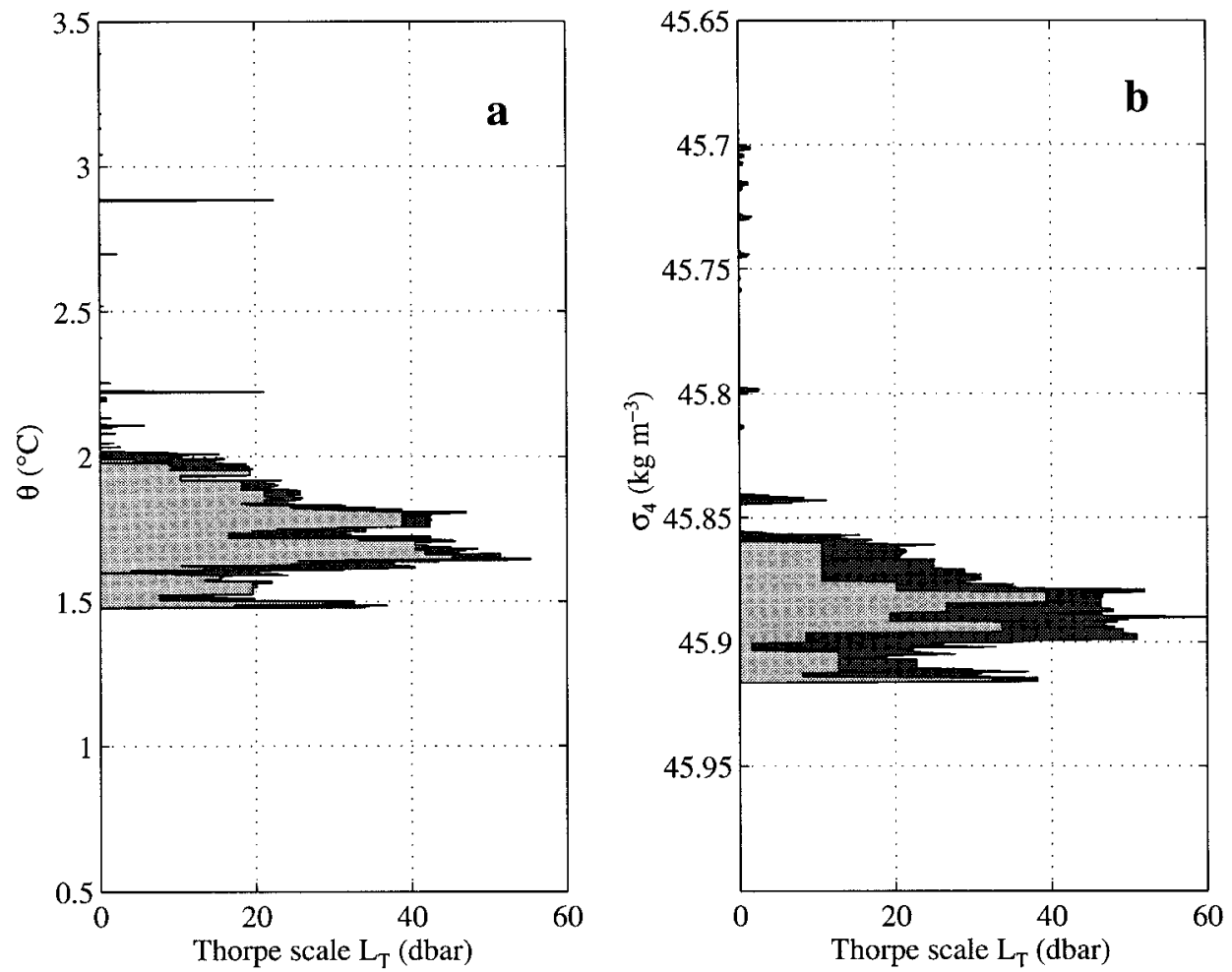

FIG. 7. Thorpe scales at the northern exit region as an average over eight casts taken during the Romanche 3 cruise. (a) Thorpe scales calculated with temperature, same noises as Fig. 4. (b) Thorpe scales calculated with density, same noises as Fig. 5.

to estimate $L_{O}$, we must resolve the centimeter scales at which the turbulent kinetic energy is dissipated. The HRP gives vertical profiles of the dissipation $\varepsilon$, as well as vertical profiles of temperature and salinity needed to calculate $N^{2}$ and $L_{T}$. The choice was made to calculate

$$
N^{2}=-\frac{g}{\rho_{0}} \frac{\Delta \rho}{\Delta z}
$$

using a $\Delta z=10 \mathrm{~m}$ (see below). The ordered profile is used to estimate $N^{2}$ so that $N^{2}$ is always positive. For each HRP profile, we have first calculated $L_{T}$ from temperature, then the dissipation and $N^{2}$ have been averaged over each turbulent patch (defined as a structure for which $L_{T}$ is continuously nonzero) before estimating $L_{O}$. Here $L_{O}$ and $L_{T}$ were calculated using $16 \mathrm{HRP}$ stations located downstream of the RFZ main sill. The casts exhibit 189 turbulent patches, from which 132 are located below the $2^{\circ} \mathrm{C}$ isotherm (we have restricted ourselves to layers where $\theta \leq 2.0^{\circ} \mathrm{C}$ where $L_{T}$ depends only weakly on the instrumental noise level choice, Figs. 4 and 5). As $L_{O}$ and $L_{T}$ are two different estimates of the overturning lengths ( $L_{O}$ comes from a dimensional analysis, while $L_{T}$ is a physical measure), a linear relationship is expected between these two parameters; $L_{O}$ is an estimate of turbulent outer scales from a dissipation variable, whereas $L_{T}$ represents a direct measure of the largest turbulent scales. The two are related energeti- cally by the turbulent cascade process. An exact linear relation is not expected due to spatial and temporal variability of the turbulent field and possible restratification effects. The $L_{T}, L_{O}$ relationship is only a statistical one. Dillon (1982) was the first to plot $L_{O}$ against $L_{T}$. Tables 1 and 2 from Dillon (1982) give the relation $L_{O}=0.79 L_{T}$ for an actively mixing surface layer and seasonal thermocline at Ocean Weather Station $\mathrm{P}\left(50^{\circ} \mathrm{N}, 145^{\circ} \mathrm{W}\right)$ during the MILE experiment. Since then, other studies revealed such a relation (Table 2). However, these studies occurred in the thermocline region or laboratory experiments.

Figure 9 is a $\log -\log$ scatterplot of $L_{O}$ versus $L_{T}$. The linear relationship between $L_{O}$ and $L_{T}$ has been calculated by minimizing the sum of the absolute values of the orthogonal distances between data points and a degree-one polynomial, as uncertainties exist in both length scales. A robust estimation $\left(L_{1}\right)$ was used to fit the line in order to give less weight to outliers (e.g., Press et al. 1995). The relation so found is

$$
L_{O}=0.95 L_{T} .
$$

Wijesekera et al. (1993) show for their data that $L_{O} / L_{T}$ is lognormal distributed. Our dataset also follows a lognormal distribution with a mean value of -0.1 and a standard deviation of 0.7 . Hence, $\ln \left(L_{O} / L_{T}\right)=-0.1 \pm$ 0.7 or, equivalently, $L_{O} / L_{T}$ belongs to $[0.3,1.8]$. For 


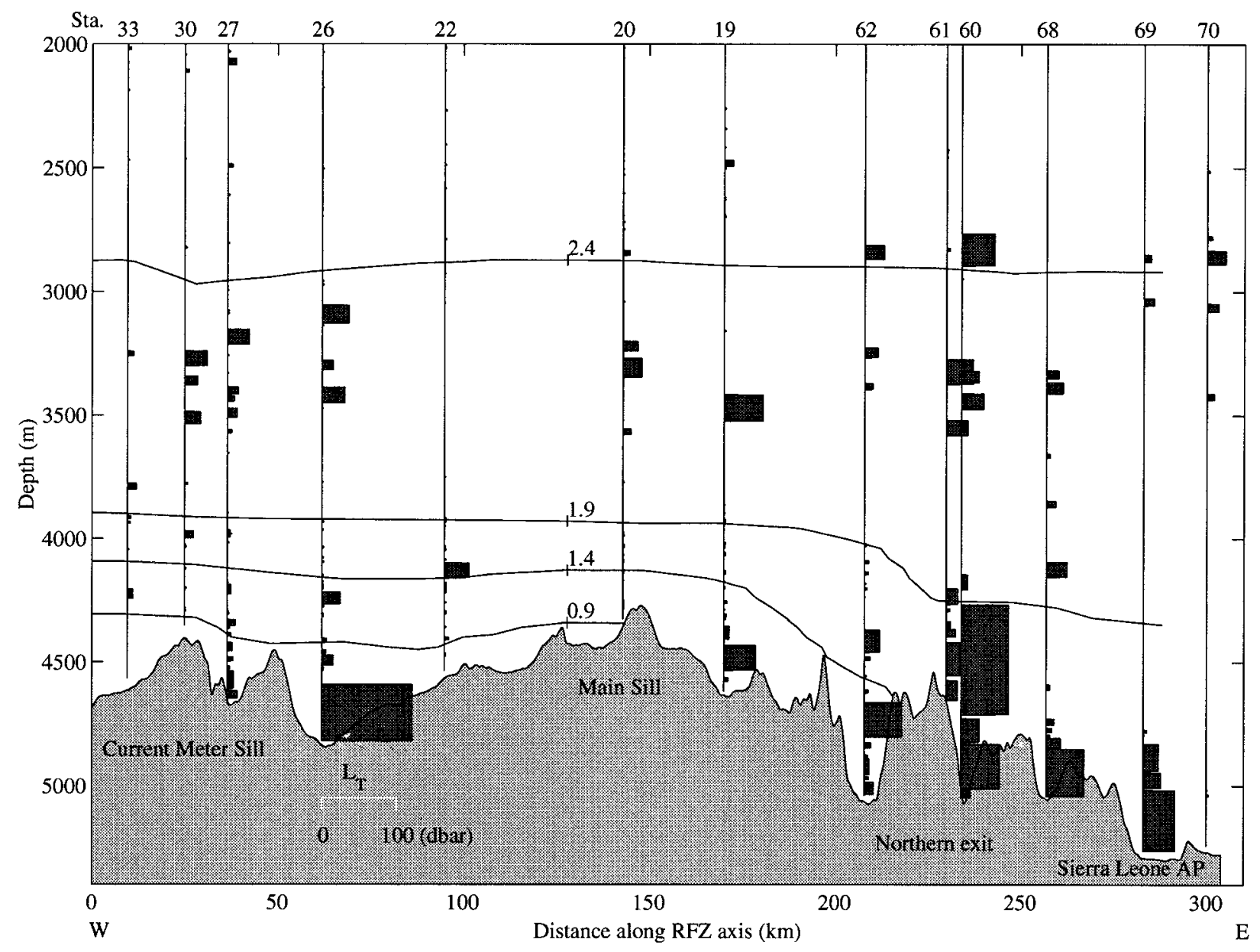

FIG. 8. Evolution of the Thorpe scales (dbar) along the RFZ valley (station locations are indicated in Fig. 3). Thorpe scales $L_{T}$ were calculated with temperature with a noise level of $0.001{ }^{\circ} \mathrm{C}$ (see appendix for details). Each block corresponds with a turbulent patch. The horizontal length of the block is equal to $L_{T}$. The vertical length is equal to the height of the overturn. The distinction between two turbulent patches was done if they were separated by more than 5 dbar. The position of 4 isotherms is also given.

comparison, the standard deviation of $L_{O} / L_{T}$ is 0.6 , which leads to $L_{O} / L_{T}$ in $[0.3,1.5]$.

\section{d. Comparison between the dissipation estimated from $L_{T}$ and the dissipation measured by the HRP}

In order to estimate $\epsilon$ from $L_{T}$, we use the relationship $L_{O}=a L_{T}$ between the Ozmidov scale and the Thorpe scale, which yields

TABLE 2. Studies of the linear relation between the Ozmidov scale and the Thorpe scale $\left(L_{O} / L_{T} \pm 1\right.$ standard deviation).

\begin{tabular}{|c|c|c|}
\hline Author & Location & Relation $L_{O}=f\left(L_{T}\right)$ \\
\hline Dillon (1982) & $\begin{array}{l}\text { Seasonal oceanic } \\
\text { thermocline }\end{array}$ & $L_{O}=0.79( \pm 0.4) L_{T}$ \\
\hline Itsweire (1984) & Grid turbulence & $L_{O}=0.65( \pm 0.1) L_{T}$ \\
\hline Crawford (1986) & $\begin{array}{l}\text { Permanent oceanic } \\
\text { thermocline }\end{array}$ & $L_{O}=0.66( \pm 0.27) L_{\tau}$ \\
\hline This paper & Ocean $\theta<2^{\circ} \mathrm{C}$ & $L_{O}=0.95( \pm 0.6) L_{T}$ \\
\hline
\end{tabular}

$$
\overline{\boldsymbol{\epsilon}}=a^{2} \overline{\left\langle N^{3}\right\rangle L_{T}^{2}},
$$

where angle brackets denote an average over turbulent patches, the overbar denotes an average over vertical profiles, the buoyancy frequency $\mathrm{N}$ is estimated over a $10-\mathrm{m}$ scale, and the Thorpe scales are calculated using the finescale potential temperature of the HRP with a noise level of $10^{-3}{ }^{\circ} \mathrm{C}$. Results are presented in Fig. 10, for which $16 \mathrm{HRP}$ stations located downstream of the main sill have been used (the same stations as in section $3 c$ ). In order to be consistent with the estimate of $\epsilon$ from $L_{T}$, which is piecewise constant, the HRP dissipation was averaged over each turbulent patch and then averaged over the profiles as a function of the potential temperature (HRP1 profile). The limitation of this method is that when $L_{T}=0$, the measured dissipation is not necessarily zero but is disregarded. A direct average of the HRP dissipation was also calculated and then lowpass filtered (HRP2 profile). In addition, profiles were grouped and averaged by regions, then regions were 
weighted by areas to produce the final averaged profiles. Figure 10 shows that the three profiles are qualitatively similar. The estimate of the dissipation from $L_{T}$ tends to be larger than the HRP1 estimate, but smaller than the HPR2 estimate. At a given potential temperature, differences between the estimate of $\epsilon$ from $L_{T}$ and the two other estimates are sometimes larger than $50 \%$, which illustrates the statistical character of the relation between the Ozmidov scale and the Thorpe scale. However, the mean value of the estimate of the dissipation from $L_{T}$ below $2^{\circ} \mathrm{C}$ shows differences of only $15 \%$ from the two mean HRP dissipation values. This shows that a suitable averaging can considerably reduce the dispersion in the relationship between $L_{O}$ and $L_{T}$ obtained from individual turbulent patches (Fig. 9) and can lead to meaningful estimates of the dissipation. The same averaging will be used in the following for estimating $K_{\rho}$ from $L_{T}$. This satisfying result validates the use of the Thorpe scales calculated with the finestructure to infer the turbulent kinetic energy dissipation rate.

\section{Estimates of vertical mixing coefficients}

\section{a. Finestructure estimates}

The turbulent kinetic energy (TKE) is locally modified by (e.g., Kundu 1990) 1) a spatial redistribution of this energy, 2) the work done by the turbulent pressure gradient on the turbulent velocity field, 3 ) the production $P$ of TKE at the expense of the mean kinetic energy, 4) the production (destruction) $B$ of TKE by decrease (increase) in the potential energy, and 5) the dissipation $\epsilon$. As discussed by Moum (1990) and Gargett (1993), we do not know how to measure terms 1) and 2) nor in which circumstances we may disregard them. So, for practical reasons, they are neglected. Therefore, for a one-dimensional stratified sheared flow in steady state $U(z)$, the TKE equation reduces to

$$
\begin{gathered}
-\overline{u^{\prime} w^{\prime}} \partial_{z} U=\frac{g}{\bar{\rho}} \overline{w^{\prime} \rho^{\prime}}+\epsilon, \\
P \quad B \quad \epsilon
\end{gathered}
$$

where the overbar denotes an appropriate average, the prime a fluctuation from this average; $u^{\prime}$ and $w^{\prime}$ are the fluctuations of the horizontal and vertical velocity components. Following Holt et al.'s (1992) and Itsweire et al.'s (1993) works based on numerical studies of homogeneous turbulence generated in a stratified sheared flow, such a balance is expected at equilibrium. They showed that, at equilibrium, the Thorpe scale and the Ozmidov scale are nearly equal. Since we have demonstrated that for our set of data, $L_{O} \simeq L_{T}$ from a statistical point of view, it is then reasonable to apply Eq. (4) for estimating the eddy diffusivity.

Introducing the flux Richardson number $R_{f}=B P^{-1}$, and making the assumption that the buoyancy flux $\overline{w^{\prime} \rho^{\prime}}$ may be represented as $-K_{\rho} \partial_{z} \bar{\rho}$ by analogy with the molecular fluxes, yields Osborn's (1980) model:

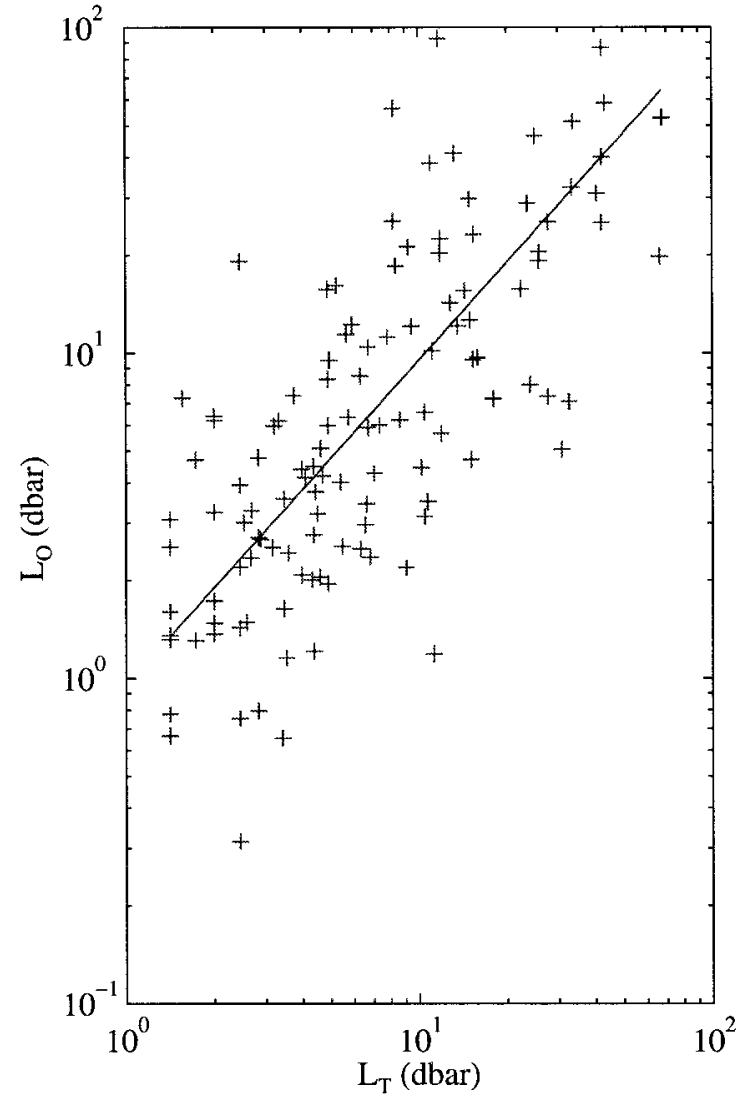

FIG. 9. Scatterplot of the Thorpe scale $L_{T}$ against the Ozmidov scale $L_{O}\left(\right.$ Ozmidov 1965) for $\theta \leq 2^{\circ} \mathrm{C}$. The relation $L_{O}=0.95 L_{T}$ found with our dataset is similar to other studies (Table 2).

$$
K_{\rho}=\Gamma \epsilon N^{-2}
$$

where

$$
\Gamma=\frac{R_{f}}{1-R_{f}}=\frac{B}{\epsilon}
$$

and $\Gamma$, referred to as the mixing efficiency, represents the ratio of TKE converted into potential energy to TKE dissipated. This mixing efficiency is commonly taken to be 0.2 . However, as noted by Caldwell and Moums (1995), $\Gamma$ is far from being a constant and may strongly depend on the type of instability causing the turbulence (Wijesekera et al. 1993). For instance, Oakey (1982) found from concurrent measurements of TKE dissipation and variance of temperature dissipation that $\Gamma=$ $0.26 \pm 0.21$ near the sea surface under a variety of wind and wave conditions, while Gargett and Moum (1995) found $\Gamma=0.7$ in a strongly convergent tidal channel flow. Studying the mixing of the Mediterranean outflow downstream of the Strait of Gibraltar, in a dynamical context that might be similar to that of the Romanche Fracture Zone, Wesson and Gregg (1994) use $\Gamma=0.2$. As we cannot estimate $\Gamma$, we use the 0.2 value in the following. 


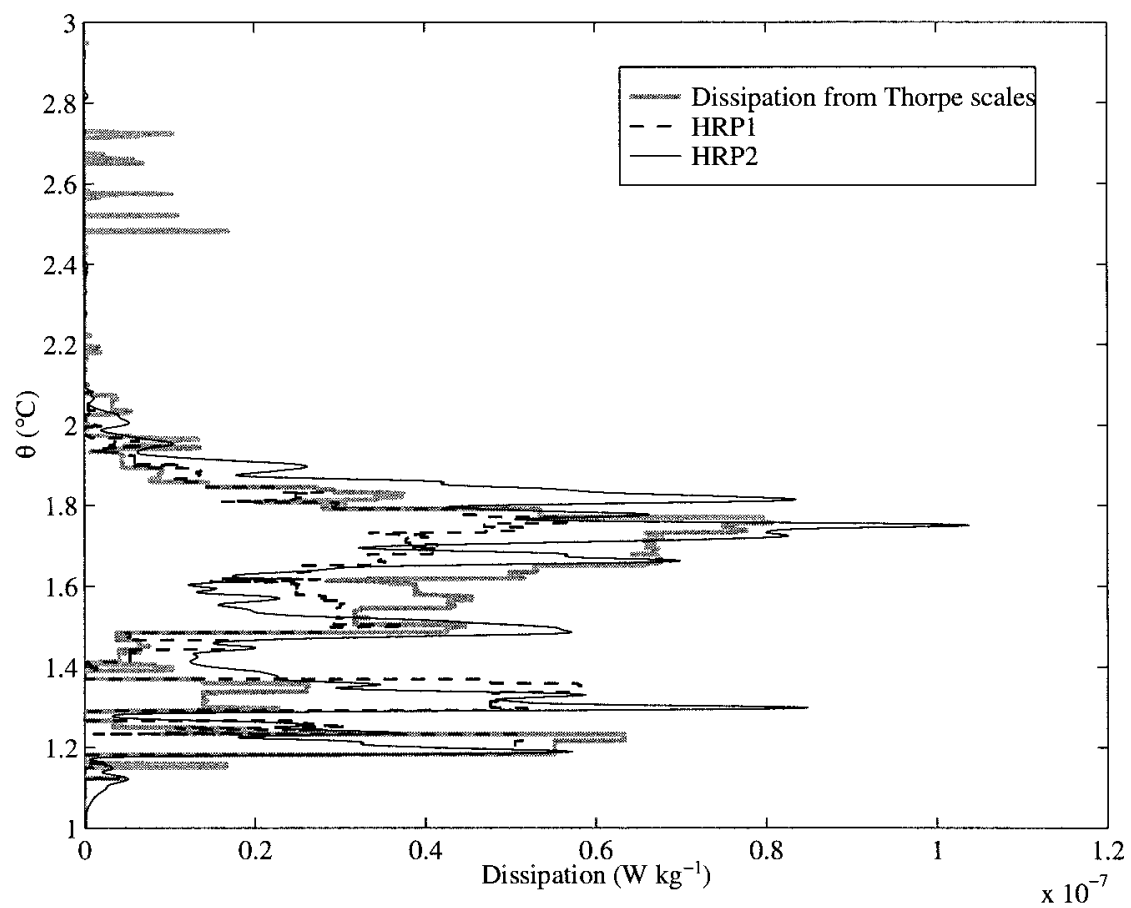

FIG. 10. Averaged dissipation of turbulent kinetic energy over 16 HRP stations estimated from 1) Thorpe scales calculated with the finestructure of the potential temperature (noise level $10^{-3}$ $\left.{ }^{\circ} \mathrm{C}\right)$, 2) the measured dissipation preaveraged over Thorpe scales (HRP1), 3) the measured dissipation directly averaged as a function of the potential temperature (HRP2).

Combining the relation $L_{O}=a L_{T}$ derived in section 3 with Eq. (1) yields

$$
\epsilon=a^{2} N^{3} L_{T}^{2},
$$

where $N^{3}$ in (6) and $N^{-2}$ in (5) could be distinguished as $N^{3}$ should be calculated as $L_{T}^{2}$ over each turbulent patch while $N^{-2}$, coming from the parameterization of $\overline{w^{\prime} \rho^{\prime}}$, should not necessarily be calculated on the same scales as $L_{T}^{2}$. However, for the sake of simplicity we choose not to do so. Combining (6) and (5) and averaging over several profiles yields

$$
\overline{K_{\rho}}=a^{2} \Gamma \overline{\langle N\rangle L_{T}^{2}}
$$

where $a=0.95$ comes from Eq. (2), $\Gamma=0.2$, the buoyancy frequency $N$ is estimated over a 10-m vertical scale (the same scale as before), the angle brackets denotes a mean over $L_{T}$, and the overbar an average over all the profiles available in a given geographic region. In Fig. $11 \overline{K_{\rho}}$ are plotted for the northern exit and the current meter regions. The Thorpe scales used were those calculated with temperature that nearly equal to those calculated with density so that $\overline{K_{T}}$ cannot be distinguished from $\overline{K_{\rho}}$. Table 3 presents $\overline{K_{\rho}}$ by temperature classes. For temperatures lower than $2^{\circ} \mathrm{C}$, the northern exit exhibits a mean value $\overline{K_{\rho}}=1000 \times 10^{-4} \mathrm{~m}^{2} \mathrm{~s}^{-1}$, consistent with the observed eastward warming of bottom waters in this region (Fig. 2). This extreme value is an order of magnitude greater than the value found for the bottom layer $\left(\theta \leq 0.9^{\circ} \mathrm{C}\right)$ at the current meter sill where $\overline{K_{\rho}}=$
$91 \times 10^{-4} \mathrm{~m}^{2} \mathrm{~s}^{-1}$. These large mixing coefficients generated by mechanical mixing contrast with Polzin et al.'s (1996) middepth diffusivity of $0.2 \times 10^{-4} \mathrm{~m}^{2} \mathrm{~s}^{-1}$ in this region produced by the internal wave field.

The estimate of $\overline{K_{\rho}}$ from (7) depends on many assumptions. It is not totally clear if these assumptions are really justified and, if they are, under which conditions. In addition, errors in the estimate of $a^{2} \Gamma$ can be as large as an order of magnitude. These limitations could be a source of discrepancy between the estimates of $\overline{K_{\rho}}$ resulting from microstructure measurements using Osborn's (1980) relation and the estimates of $\overline{K_{\rho}}$ resulting from heat budgets. However, the data available for this region allowed us to compare $\overline{K_{\rho}}$ presented above and another estimate from long-term current meter data. It will be shown that the two estimates converge.

\section{b. Heat budget estimates}

Temperature-current meters were deployed for a period of $2 \mathrm{yr}$ near the entrance of the RFZ and CFZ (Mercier and Speer 1998). As the bottom water flows eastward downstream of the current meter moorings, it warms and the coldest isotherms vanish. Following Hogg et al. (1982) or Whitehead and Worthington (1982), one may construct a heat budget for a volume delimited by the current meter moorings and an isothermal surface reaching the ground downstream of the 

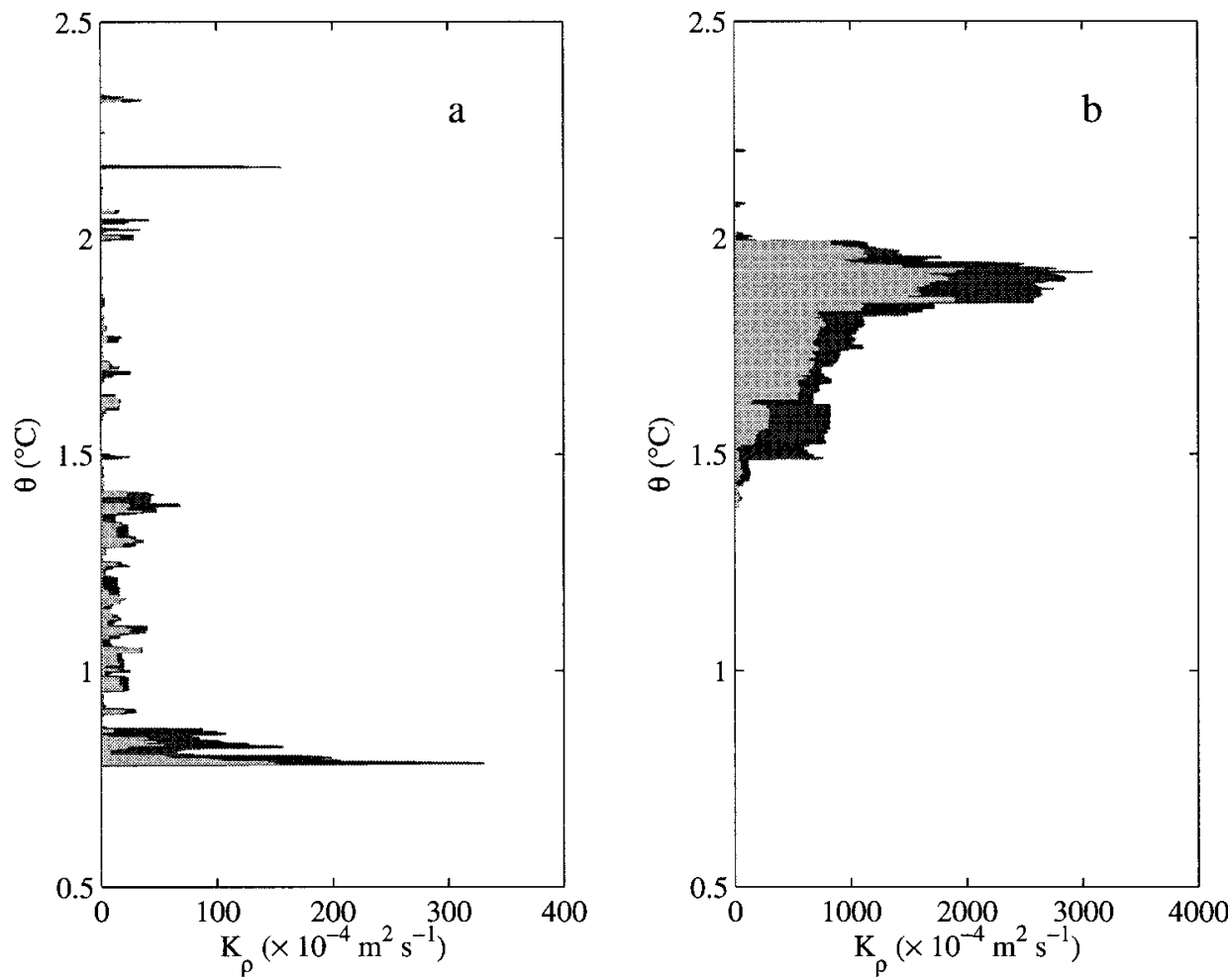

FIG. 11. (a) Estimate of $\overline{K_{\rho}}$ as a function of temperature for data taken at the current meter region using Eq. (7) deduced from Osborn's (1980) relation. Thorpe scales were calculated from temperature profile. Dark gray is associated with the minimum noise $\delta=0.001{ }^{\circ} \mathrm{C}$, while light gray curve corresponds with four times of this noise. (b) Same estimate for the northern exit.

current meter moorings (Fig. 12). A mean balance between the entering advective heat flux across the mooring section, the exiting advective flux and the diffusive heat flux across the isothermal surface is supposed, yielding the formula

$$
K_{T}=\frac{Q^{\text {net }}}{A \partial_{z} \theta},
$$

where $Q^{\text {net }}$ is the net advective flux into the box, $\partial_{z} \theta$ is the mean vertical temperature gradient across the isothermal surface of area $A$ and potential temperature $\theta_{s}$; $Q^{\text {net }}=\rho C_{p}\left(\langle U h \theta\rangle-A w \theta_{s}\right)$, where $C_{p}$ is the specific

TABLE 3. Estimate of $\overline{K_{\rho}}$ by layers of potential temperature at the current meter region and the northern exit. Thorpe scales were calculated with temperature. Same casts and noise level as in Table 1.

\begin{tabular}{cccc}
\hline \hline $\begin{array}{c}\text { Geographic } \\
\text { region }\end{array}$ & Layer $\left({ }^{\circ} \mathrm{C}\right)$ & $\begin{array}{c}\text { Noise } \\
\text { level }\end{array}$ & $\begin{array}{c}\overline{\overline{K_{\rho}}}=0.18 \overline{L_{T}^{2} N} \\
\left(\times 10^{-4} \mathrm{~m}^{2} \mathrm{~s}^{-1}\right)\end{array}$ \\
\hline Current meter & $0.9 \leq \theta \leq 2.0$ & $\delta$ & 9.7 \\
& $\theta \leq 0.9$ & $4 \delta$ & 4.0 \\
Northern exit & $1.7 \leq \theta \leq 2.0$ & $\delta$ & 91 \\
& $\theta \leq 1.7$ & $4 \delta$ & 24 \\
& & $\delta$ & 1600 \\
& & $4 \delta$ & 540 \\
\hline
\end{tabular}

heat, $U h$ is the transport of water colder than $\theta_{s}$, angle brackets denote a time average, and $A w$ is the timeaveraged cross-isothermal transport across $A$, which equals $\langle U h\rangle$ by continuity. Potential temperature and current time series were correlated for calculating the entering heat flux. Two isotherms $\left(\theta=0.9^{\circ} \mathrm{C}\right.$ and $\theta=$ $\left.1.2^{\circ} \mathrm{C}\right)$ vanishing in the RFZ, two isotherms $\left(\theta=1.0^{\circ} \mathrm{C}\right.$ and $\theta=1.3^{\circ} \mathrm{C}$ ) vanishing in the $\mathrm{CFZ}$, and two isotherms $\left(\theta=1.7^{\circ} \mathrm{C}\right.$ and $\left.\theta=1.8^{\circ} \mathrm{C}\right)$ vanishing in the Sierra Leone and Guinea Abyssal Plains were considered, resulting in six estimates of $K_{T}$. For these two last isotherms, the heat flux entering the CFZ was added to the one entering the RFZ to calculate the heat budget. For the isotherms vanishing in the RFZ and CFZ, the areas A were estimated using the high-resolution bathymetric map and Romanche-Romel CTD data. For $\theta=1.7^{\circ}$ and $1.8^{\circ} \mathrm{C}$, areas were determined with CTD data from Cither 1 (Arhan et al. 1998) and Romanche cruises and the ETOPO5 bathymetric dataset. The results for the RFZ and downstream abyssal plains are shown in Fig. 12. Detailed information including the results obtained in the CFZ are summed up in Table 4. Uncertainties result from errors in the determination of both the temperature gradients and the areas of the isotherms. Before comparing the finestructure results with those of the heat budget, we must keep in mind that the former are local 


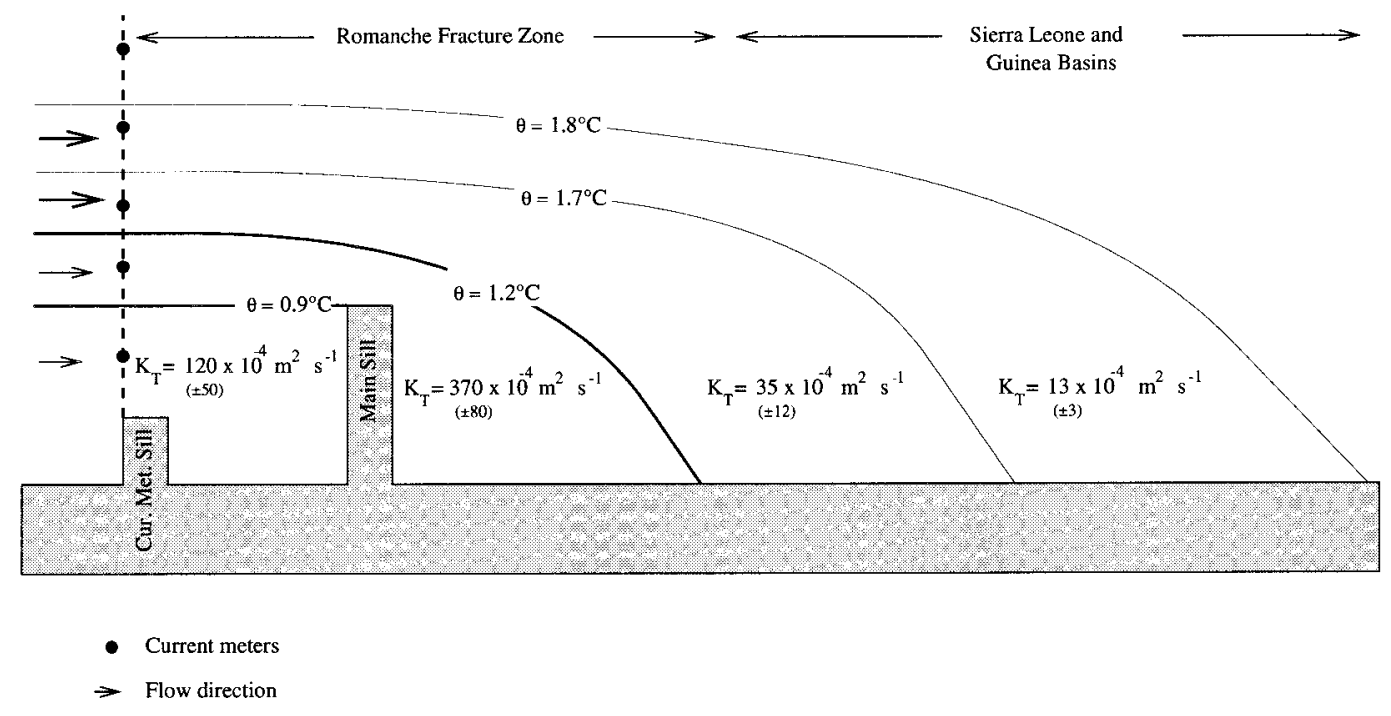

FIG. 12. Estimate of cross-isothermal eddy diffusivity from heat budgets. The isotherms $0.9^{\circ}$ and $1.2^{\circ} \mathrm{C}$ vanish in the Romanche Fracture Zone, whereas the $1.7^{\circ}$ and $1.8^{\circ} \mathrm{C}$ lie in the downstream abyssal plains. The uncertainties displayed under each estimate mainly come from the determination of the temperature gradients (Table 4).

estimates, whereas the latter give an integral view of the mixing, both in time (a mean over two years) and space (over the area of the isotherms).

Between the current meter sill and the main sill in the RFZ, for $\theta<0.9^{\circ} \mathrm{C}, K_{T}=120( \pm 50) \times 10^{-4} \mathrm{~m}^{2}$ $\mathrm{s}^{-1}$. This value is in agreement with $K_{\rho}$ estimated from temperature finestructure at the current meter sill $\left(K_{\rho}=\right.$ $\left.91 \times 10^{-4} \mathrm{~m}^{2} \mathrm{~s}^{-1}\right)$, even though the finestructure study only concerned a small portion of enhanced mixing of the water colder than $0.9^{\circ} \mathrm{C}$, from station 30 to station 27 (Fig. 8). For $\theta<1.2^{\circ} \mathrm{C}$, we have supposed that, upstream of the main sill, vertical advection and mixing coefficient $K_{T}$ were equal to those found for $\theta<0.9^{\circ} \mathrm{C}$. Such an assumption is consistent with the view of intensified mixing downstream of the main sill. Downstream of the main sill $K_{T}$ equals $370( \pm 80) \times 10^{-4} \mathrm{~m}^{2}$ $\mathrm{s}^{-1}$, which is a factor of 3 greater than the upstream value. This value is of the same order of magnitude as $K_{\rho}=1000 \times 10^{-4} \mathrm{~m}^{2} \mathrm{~s}^{-1}$ given for $\theta \leq 2.0^{\circ} \mathrm{C}$ by the finestructure at the northern exit. Even if the northern exit lies outside the area covered by $\theta<1.2^{\circ} \mathrm{C}$, intensified mixing exists for each basin downstream of the main sill so that one might expect such an agreement. As for $\theta=1.7^{\circ} \mathrm{C}$ and $\theta=1.8^{\circ} \mathrm{C}$ surfaces, which ground in the Sierra Leone and Guinea Abyssal Plains, respective values of $35( \pm 12) \times 10^{-4} \mathrm{~m}^{2} \mathrm{~s}^{-1}$ and $13( \pm 3) \times$ $10^{-4} \mathrm{~m}^{2} \mathrm{~s}^{-1}$ are found, indicating that mixing across these isotherms is relatively intense. For comparison, Hogg et al. (1982) reported integrated values of $4 \times$ $10^{-4} \mathrm{~m}^{2} \mathrm{~s}^{-1}$ for the bottom water in the Brazil Basin. In order to quantify the global effect of the RFZ and CFZ on the mixing of dense waters, the diffusive heat flux across the $1.4^{\circ} \mathrm{C}$ surface has been calculated. This isotherm grounds just outside of the two fractures. Despite the fact that the area occupied by the RFZ and
CFZ is $0.4 \%$ of the one covered by the downstream abyssal plains, the diffusive heat flux across $1.4^{\circ} \mathrm{C}$ in the RFZ and CFZ is half that through the isotherm $1.8^{\circ} \mathrm{C}$ in the abyssal plains. This emphasizes the important role played by these two fracture zones for the deep- and bottom-water mass modifications.

\section{Discussion}

Diapycnal mixing in the Romanche and Chain Fracture Zones has been examined using the finestructure of CTD profiles and by constructing a heat budget from current meter data. Near the seafloor of the RFZ, the turbulence is mainly concentrated downstream of the sills, whereas at the sills it is rather weak. Although we note local variations of the intensity and vertical structure of the overturnings, which may be attributed to spatial or temporal evolution, the different cruises that visited the RFZ over a 3-yr period suggest the same spatial distribution of the turbulence.

The Ozmidov scale is related here to the Thorpe scale by: $L_{O}=0.95 L_{T}$ for $\theta<2{ }^{\circ} \mathrm{C}$. This relation, similar to other studies, has allowed us to estimate the dissipation rates of the turbulent kinetic energy from Thorpe scales contained in finescale vertical temperature or density profiles. It was shown that the dissipation estimate from $L_{T}$ is close to the microstructure estimate of the dissipation. This result encourages similar analyses of existing datasets as finescale vertical profiles are much more widely measured than microscale vertical profiles.

A simplified form for the diapycnal advection $w_{\epsilon}^{d}$ of potential density due to the diapycnal flux divergence may be inferred from McDougall's (1991) Eq. (20): 
TABLE 4. Cross-isothermal eddy diffusivity estimated from the current meter data for several isotherms $\theta$. The location where the isotherm vanishes is displayed in the first column. $Q^{\text {net }}$ is equal to the diffusive heat flux across the isotherm that balances the advective heat fluxes. Cross-isothermal velocities $(w)$ and area $(A)$ covered by $\theta$ are also given. For $\theta=1.2^{\circ} \mathrm{C}$, two coefficients were estimated: (a) is a mean over the whole surface while (b) gives an estimate downstream of the main sill with the assumption that enhanced mixing is present here as suggested by the CTD data.

\begin{tabular}{cccccc}
\hline \hline Location & $\begin{array}{c}\theta \\
\left({ }^{\circ} \mathrm{C}\right)\end{array}$ & $\begin{array}{c}Q^{\text {net }} / \rho C_{p} \\
\left({ }^{\circ} \mathrm{C} \mathrm{m}^{3} \mathrm{~s}^{-1}\right)\end{array}$ & $\begin{array}{c}w \\
\left(\mathrm{~m} \mathrm{~s}^{-1}\right)\end{array}$ & $\begin{array}{c}A \\
\left(\mathrm{~m}^{2}\right)\end{array}$ & $\begin{array}{c}K_{T} \\
\left(\times 10^{-4} \mathrm{~m}^{2} \mathrm{~s}^{-1}\right)\end{array}$ \\
\hline RFZ & 0.9 & $8.1 \times 10^{3}$ & $1.7 \times 10^{-4}$ & $0.736 \times 10^{9}$ & $120 \pm 50$ \\
RFZ & 1.2 & $6.8 \times 10^{4}$ & $1.4 \times 10^{-4}$ & $1.90 \times 10^{9}$ & $150 \pm 30(\mathrm{a})$ \\
CFZ & 1.0 & $7.3 \times 10^{3}$ & $6.7 \times 10^{-5}$ & $1.20 \times 10^{9}$ & $370 \pm 80(\mathrm{~b})$ \\
CFZ & 1.3 & $5.2 \times 10^{4}$ & $1.3 \times 10^{-4}$ & $1.7 \times 10^{9}$ & $50 \pm 2 \pm 30$ \\
Abyssal plain & 1.7 & $4.4 \times 10^{5}$ & $1.8 \times 10^{-6}$ & $486 \times 10^{9}$ & $35 \pm 12$ \\
Abyssal plain & 1.8 & $4.7 \times 10^{5}$ & $9.3 \times 10^{-7}$ & $1100 \times 10^{9}$ & $13 \pm 3$ \\
\hline
\end{tabular}

$$
w_{\epsilon}^{d} \frac{1}{\rho_{\theta}} \frac{\partial \rho_{\theta}}{\partial z}=\frac{\partial}{\partial z}\left(K_{\rho} \frac{1}{\rho_{\theta}} \frac{\partial \rho_{\theta}}{\partial z}\right),
$$

where $w_{\epsilon}^{d}$ is the diapycnal velocity tendency due to the mixing associated with the dissipation $\epsilon, K_{\rho}$ the vertical eddy diffusivity of density, $\rho_{\theta}$ the potential density, and $z$ the vertical direction. Combining Eqs. (5) and (9) yields

$$
w_{\epsilon}^{d}=N^{-2} \frac{\partial(\Gamma \epsilon)}{\partial z} .
$$

Figure 10 shows that at the northern exit above $2^{\circ} \mathrm{C}$, the dissipation is nearly constant (at low values), which implies that the vertical mixing does not produce any significant diapycnal velocity trend. Around $1.8^{\circ} \mathrm{C}$, the dissipation is maximum so that $w_{\epsilon}^{d}$ is again weak, and the upwelling across this isotherm occurs outside the RFZ in the downstream abyssal plains. Between $2^{\circ}$ and $1.8^{\circ} \mathrm{C}$, a downwelling trend is diagnosed. The mean value is $w_{\epsilon}^{d}=$ $0.75 \times 10^{-4} \mathrm{~m} \mathrm{~s}^{-1}$ for the isotherm $1.9^{\circ} \mathrm{C}$. Multiplying this diapycnal velocity by the area $\left(1.3 \times 10^{9} \mathrm{~m}^{2}\right)$ of the $1.9^{\circ} \mathrm{C}$ surface near the exit leads to a diapycnal transport of $0.1 \mathrm{~Sv}$. The mixing tends to increase the transport of AABW downstream of the main sill. Mercier and Speer (1997) also found that entrainment across the $1.9^{\circ} \mathrm{C}$ is necessary to match direct and indirect estimates of the transport of AABW. However, it is difficult to estimate accurately the diapycnal transport across the $1.9^{\circ} \mathrm{C}$ surface using our dataset since 1) other terms are present in the expression of the diapycnal velocity (McDougall 1991) that we are unable to estimate reliably but simple scaling arguments suggests they are small and 2) further significant mixing and downwelling across $1.9^{\circ} \mathrm{C}$ may occur in other downstream basins.

The Osborn (1980) relation was used to estimate a vertical eddy diffusivity versus density for two regions of the RFZ. The strongest mixing was found at the northern exit with a maximum close to $2000 \times 10^{-4} \mathrm{~m}^{2} \mathrm{~s}^{-1}$. In this region, enhanced mixing appears over $1000 \mathrm{~m}$ above the bottom. This contrasts with the current meter region where the peak of mixing is an order of magnitude lower and only occurs at the highest densities, in the near-bottom layer.

Heat budgets from the current meter data for $\theta=$ $1.2^{\circ} \mathrm{C}$, which yield a cross-isothermal eddy diffusivity of $370( \pm 80) \times 10^{-4} \mathrm{~m}^{2} \mathrm{~s}^{-1}$, show good agreement with the study of finestructure at the northern exit, which gave a mean diffusivity below $2^{\circ} \mathrm{C}$ of $1000 \times 10^{-4} \mathrm{~m}^{2}$ $\mathrm{s}^{-1}$. Thus, the discrepancy often mentioned between fine- or microstructure estimates and heat budget estimates of $K_{\rho}$ is not present in this local study. This tends to confirm that the discrepancy may exist because the nature of the estimates are different, as suggested by Toole et al. (1994). The heat budgets give an integral view of the mixing, while the fine- or microstructure data are local estimates that strongly depend on sampling strategy. In this study the heat budget is done in the known location of the mixing, whereas in budgets done over larger areas, the microscale estimates may not be taken in the area of enhanced mixing, and consequently a discrepancy may exist.

Perhaps the most striking feature from the current meter data is the importance of the equatorial RFZ and CFZ in the modification of the deep and bottom waters. Although the two fractures occupy only $0.4 \%$ of the area covered by the Sierra Leone and Guinea Abyssal Plains, the diffusive heat fluxes in the RFZ and CFZ are as large as half of those produced by the abyssal plains. This emphasizes that the role played by mixing in restricted passages is a major component of the heat flux transfers between deep and bottom water masses, and exerts a significant control on the thermohaline circulation equilibrium.

Acknowledgments. This work was supported in part by the Centre National de la Recherche Scientifique (CNRS/INSU), the Institut Français de Recherche pour l'Exploitation de la Mer (IFREMER) through the French Programme National d'Etude de la Dynamique du Climat (PNEDC). B.F. is supported by IFREMER, H.M. and K.G.S. by CNRS, and K.L.P. by NSF Grant OCE 93-01223. Support for AEG was received from IFREMER and the Department of Fisheries and Oceans Canada under the program for Franco-Canadian Cooperation in Marine Science and Technology. Stimulating discussions with Anne-Marie Treguier are acknowledged. 


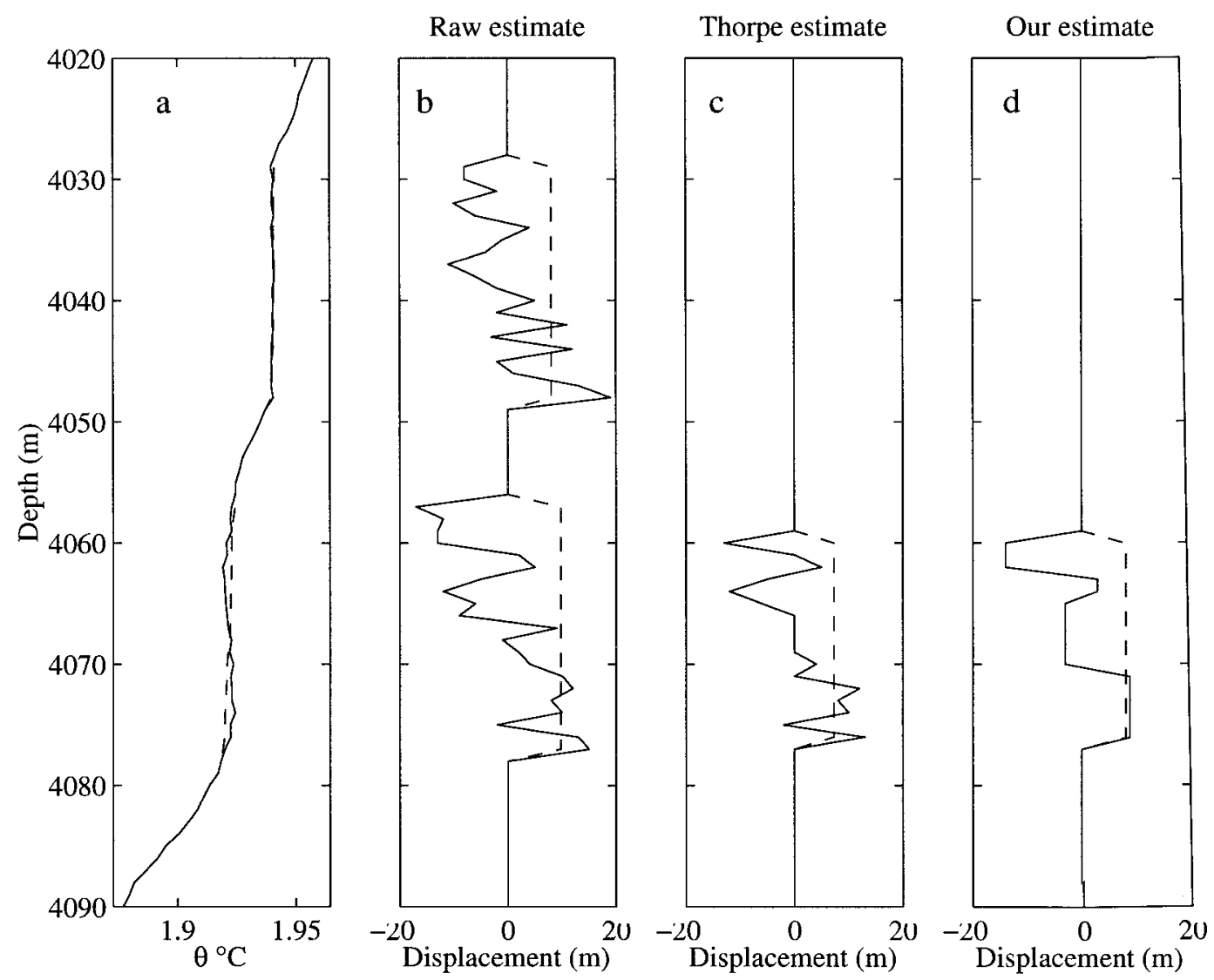

FIG. A1. (a) Vertical raw temperature profile (solid line) and ordered temperature profile (dotted line). (b) Displacements obtained by using the raw data. (c) Displacements obtained using Thorpe's method. The noise is $0.002^{\circ} \mathrm{C}$. Note that Thorpe's method does not reveal inversion in the weak temperature gradient region. (d) Displacements obtained using our method are described in the appendix. The noise is still $0.002^{\circ} \mathrm{C}$.

\section{APPENDIX}

\section{An Algorithm for Calculating the Thorpe Scale}

The Thorpe scale (Thorpe 1977) $L_{T}$ is an index for studying, qualitatively as well as quantitatively, turbulence in stratified fluids. Before significant molecular diffusion has occured, $L_{T}$ is a measure of the lengths of the overturns locally produced by instabilities. However, as $L_{T}$ is estimated using a sorting algorithm rather than an arithmetic formula, the reliability of the result is not easily assessed by standard methods. The purpose of this appendix is to suggest a calculation method that ensures computed values of $L_{T}$ are consistent with the relative accuracy of the measured variable used to calculate it.

Working in freshwater, Thorpe (1977) first introduced the concept of ordering a measured profile of temperature for obtaining a gravitationally stable profile. He interpreted the difference $d_{T}=z_{0}-z_{r}$ between the original $\left(z_{0}\right)$ and ordered $\left(z_{r}\right)$ positions as an estimate of the vertical displacement associated with turbulent motions. This interpretation is based upon the simple picture of an eddy of vertical length height $l$ acting on a stable mean vertical density gradient $\rho_{z}$ to produce density fluctuations of order $\rho^{\prime}=l \rho_{z}$. From a measured vertical profile of density, $l$ is estimated by the minimum vertical distance a parcel of fluid must be moved in order to obtain a stable density profile including unstable patches, while $\rho_{z}$ is calculated by vertical differentiation of this resultant stable density profile. Considering a gravitationally unstable patch, $L_{T}$ is defined as the rms of the displacements obtained for this patch.

The accuracy of computation of the displacements $d_{T}$ depends upon both the noise level of the measured variable and the local mean vertical gradient of that variable. This is readily seen in an example for which we assume that density is proportional to temperature. Figure A1a shows a synthetic, assumed measured, temperature profile, created as follows. The vertical data spacing is 1 $\mathrm{m}$. The vertical temperature gradient is $2 \times 10^{-3}{ }^{\circ} \mathrm{C} / \mathrm{m}$ from 4000 to $4030 \mathrm{~m}, 10^{-5}{ }^{\circ} \mathrm{C} / \mathrm{m}$ from 4031 to 4060 $\mathrm{m}$, and again $2 \times 10^{-3}{ }^{\circ} \mathrm{C} / \mathrm{m}$ below $4060 \mathrm{~m}$. A random noise of a maximum $2 \times 10^{-3}{ }^{\circ} \mathrm{C}$ peak to peak is added to the whole column in order to model a high-frequency noise. Finally, a temperature inversion simulated by a sinusoid of $15 \times 10^{-2}{ }^{\circ} \mathrm{C}$ amplitude is added from 4050 
to $4080 \mathrm{~m}$. Figure A1a shows the temperature profile from 4020 to $4080 \mathrm{~m}$ (solid line). Ordering this raw temperature profile gives the dashed profile, then comparing it to the raw measured profile leads to the displacement of Fig. A1b. The solid line represents the displacements while the dashed line is the rms of the displacements over the whole unstable stucture. A displacement $d_{T}$ at a depth $z_{r}$ means that the associated parcel of fluid located at $z_{r}$ on the ordered profile is moved at a depth $z_{r}-d_{T}$ on the measured profile. Hence, positive (negative) displacements are associated with an upward (downward) motion. Figure A1b exhibits nonzero displacements from 4027 to $4048 \mathrm{~m}$, that is, where the temperature gradient is the weakest, and from 4056 down to $4078 \mathrm{~m}$, where the "real" temperature inversion lies. A temperature inversion may appear due to noise if the temperature gradient $T_{z}$ is sufficiently low, that is, if the maximum peak to peak noise is higher than $T_{z} \Delta_{z}$, where $\Delta_{z}^{-1}$ is the sampling rate. Thus, ordering the raw profile leads to the impossibility of making the distinction between noise inversions and real inversions.

Thorpe attempted to limit such errors by setting $d_{T}$ $=0$ unless the temperature in the measured profile differs from the temperature of the ordered profile taken at the same level by more than a noise $\delta_{T}$. Figure A1c presents the result of his method when a noise $\delta_{T}=$ $0.002^{\circ} \mathrm{C}$ is taken. (We assume that we know the noise amplitude exactly.) All the displacements located in the weakest temperature gradient have disappeared since the difference between the ordered profile and the measured profile at a fixed depth is always less than or equal to $\delta_{T}$. Thorpe's method removes the inversions produced by the random noise, but it tends to underestimate the length of the overturn by rejecting valid displacements.

To avoid this problem, we propose to use an intermediate temperature profile TI and to preprocess the raw measured profile TR as follows: 1) Select a hinge temperature value $T_{0}$ and keep it fixed for all the profiles. Given $T_{0}$ and a relative accuracy $\delta$, two temperatures can be considered as different if they differ by at least $\pm \delta$ or more generally by $n \delta$, where $n$ is an integer either positive or negative. 2) Take the first value $T R_{1}$ of the temperature profile TR and find the minimum integer $n$ such that $\left(T_{0}+n \delta\right)-T R_{1} \leq \delta$. 3) Define the first intermediate temperature as $T I_{1}=T_{0}+n \delta$. 4) Take the second value $T R_{2}$ of the raw profile and find the integer $n$ such that $\left(T I_{1}+n \delta\right)-T R_{2} \leq \delta$. It gives the second value of the intermediate profile as $T I_{2}=T I_{1}+n \delta$. For instance, if $\left|T R_{2}-T I_{1}\right|<\delta, n=0$ and $T R_{2}$ cannot be distinguished from $T I_{1}$ so that $T I_{2}=T I_{1}$. 5) Go on processing until the end of the profile. TI is finally only composed of fluctuations, and possibly overturns, which are significant to the accuracy $\delta$ of the measurement. 6) Order the intermediate profile and compare the intermediate profile to the ordered profile to evaluate the displacements and the Thorpe scales.

Figure A2 shows the measured profile (solid), the

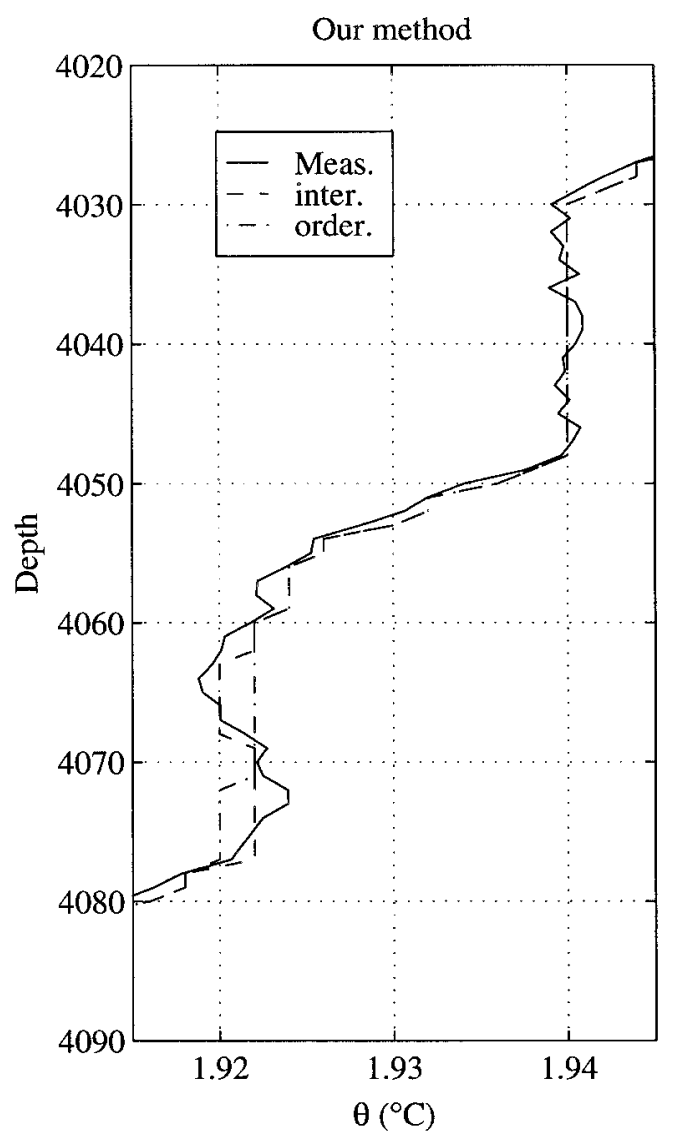

FIG. A2. Measured temperature profile (solid), intermediate temperature profile (dashed), and ordered intermediate profile (dashdotted). The noise is $0.002^{\circ} \mathrm{C}$ so that the intermediate profile is composed of fluctuations that are integer multiples of this noise.

intermediate profile (dashed), and the ordered profile (dash-dotted) when $\delta=0.002^{\circ} \mathrm{C}$. The fluctuations of the intermediate profile are some multiple of $\delta$. Figure A1d shows that, globally, displacements are greatest and more numerous than using the Thorpe algorithm (Fig. A1c) in the region where lies the "real" overturn. For the "real" overturn, estimates of the overturn height and the Thorpe scale are 23 and $10 \mathrm{~m}$ using the raw method, which blends the displacements due to the random noise, 18 and $4.8 \mathrm{~m}$ using the Thorpe method, and 18 and $8.2 \mathrm{~m}$ for our method.

\section{REFERENCES}

Arhan, M., H. Mercier, Y. Gouriou, and B. Bourles, 1998: Two zonal hydrographic sections across the Atlantic Ocean at $7^{\circ} 30^{\prime} \mathrm{N}$ and $4^{\circ} 30^{\prime}$ S. Deep-Sea Res., in press.

Caldwell, D. R., and J. N. Moum, 1995: Turbulence and mixing in the ocean. Rev. Geophys., 33 (Suppl.), 1385-1394.

Crawford, W. R., 1986: A comparison of length scales and decay times of turbulence in stably stratified flows. J. Phys. Oceanogr., 16, 1847-1854.

Dillon, T. M., 1982: Vertical overturns: A comparison of Thorpe and Ozmidov length scales. J. Geophys. Res., 87, 9601-9613.

Gargett, A. E., 1993: Parameterizing the effect of small-scale mixing 
in large-scale numerical models. NATO ASI Series, I (11), 185204.

- 1994: Observing turbulence with a modified acoustic Doppler current profiler. J. Atmos. Oceanic Technol., 11, 1592-1610.

- , and J. N. Moum, 1995: Mixing efficiencies in turbulent tidal fronts: Results from direct and indirect measurements of density flux. J. Phys. Oceanogr., 25, 2583-2608.

Hogg, N., P. Biscaye, W. Gardner, and W. J. Schmitz, 1982: On the transport and modification of Antarctic Bottom Water in the Vema Channel. J. Mar. Res., 40 (Suppl), 231-263.

Holt, S. E., J. R. Kossef, and J. H. Ferziger, 1992: A numerical study of the evolution and structure of homogeneous stably stratified sheared turbulence. J. Fluid Mech., 237, 499-539.

Itsweire, E. C., 1984: Measurements of vertical overturns in a stably stratified turbulent flow. Phys. Fluids, 27, 764-766.

- J. R. Kossef, D. A. Briggs, and J. H. Ferziger, 1993: Turbulence in stratified shear flows: Implications for interpreting shear-induced mixing in the ocean. J. Phys. Oceanogr., 23, 1508-1522.

Kundu, P. K., 1990: Fluid Mechanics. Academic Press, 638 pp.

Mantyla, A. W., and J. L. Reid, 1983: Abyssal characteristics of the world ocean waters. Deep-Sea Res., 30, 805-833.

McDougall, T., 1991: Parameterizing mixing in inverse models. Proc. Hawaiian Winter Workshop, SOEST Special Publication, 355386.

Mercier, H., and P. Morin, 1997: Hydrography of the Romanche and Chain Fracture Zones. J. Geophys. Res., 102, 10 373-10 389.

—, and K. G. Speer, 1998: Transport of bottom water in the Romanche Fracture Zone and the Chain Fracture Zone. J. Phys. Oceanogr., 28, 779-790.

— A. Billant, P. Branellec, P. Morin, M.-J. Messias, L. Memery, C. Thomas, and J. Honnorez, 1992: Campagne Romanche 1 : Données $\mathrm{CTDO}_{2}$, chimie et bathymétrie. Rapport interne LPO 92-02, 146 pp. [Available from Laboratoire de Physique des Oceáns, IFREMER centre de Brest, BP 70, 29280 Plouzané, France.]

—, K. G. Speer, and J. Honnorez, 1994: Flow pathways of bottom water through the Romanche and Chain Fracture Zones. DeepSea Res., 41, 1457-1477.

_, A. Billant, P. Branellec, C. Andrié, M.-J. Messias, Y. Gouriou, and C. Lagadec, 1995: Campagne Romanche 2: Données de la sonde $\mathrm{CTDO}_{2}$, mesures de salinité, d'oxygène dissous, et des chlorofluorométhanes, courantométrie acoustique Doppler. Rapport interne LPO 95-02, $382 \mathrm{pp}$. [Available from Laboratoire de
Physique des Oceáns, IFREMER centre de Brest, BP 70, 29280 Plouzané, France.] Campagne Romanche 3: mouillages de courantométrie, données CTD, courantométrie acoustique Doppler sur profil, courantométrie acoustique Doppler de coque. Rapport interne LPO 9701, 374 pp. [Available from Laboratoire de Physique des Oceáns, IFREMER centre de Brest, BP 70, 29280 Plouzané, France.]

Moum, J. N., 1990: The quest for $K_{\rho}$-Preliminary results from direct measurements of turbulent fluxes in the ocean. J. Phys. Oceanogr., 20, 1980-1984.

Oakey, N. S., 1982: Determination of the rate of dissipation of turbulent energy from simultaneous temperature and velocity shear microstructure measurements. J. Phys. Oceanogr., 12, 256-271.

Osborn, T. R., 1980: Estimates of the local rate of vertical diffusion from dissipation measurements. J. Phys. Oceanogr., 10, 83-89.

Ozmidov, R. V., 1965: On the turbulent exchange in a stably stratified ocean. Atmos. Ocean. Phys., 8, 853-860.

Polzin, K. L, K. G. Speer, J. M. Toole, and R. W. Schmitt, 1996: Intense mixing of Antarctic Bottom Water in the equatorial Atlantic Ocean. Nature, 380, 54-57.

—, J. M. Toole, J. R. Ledwell, and R. W. Schmitt, 1997: Spatial variability of turbulent mixing in the abyssal ocean. Science, 276, 93-96.

Press, H. W., S. A. Teukolsky, W. T. Vetterling, and B. P. Flannery, 1995: Numerical Recipes in C. Cambridge University Press, 994 pp.

Schmitt, R. W., J. M. Toole, R. L. Koehler, E. C. Mellinger, and K. W. Doherty, 1988: The development of a fine- and microstructure profiler. J. Atmos. Oceanic Technol., 5, 484-500.

Thorpe, S. A., 1977: Turbulence and mixing in a Scottish loch. Philos. Trans. Roy. Soc. London, A286, 125-181.

Toole, J. M., K. L. Polzin, and R. W. Schmitt, 1994: Estimates of diapycnal mixing in the abyssal ocean. Science, 264, 1120-1123.

Warren, B. A., and K. Speer, 1991: Deep circulation in the eastern South Atlantic. Deep-Sea Res., 38 (Suppl), 281-322.

Wesson, J. C., and M. C. Gregg, 1994: Mixing at Camarinal Sill in the Strait of Gibraltar. J. Geophys. Res., 99, 9847-9878.

Whitehead, J. A., and L. V. Worthington, 1982: The flux and mixing rates of Antarctic Bottom Water within the North Atlantic. J. Geophys. Res., 87, 7903-7924.

Wijesekera, H. W., T. M. Dillon, and L. Padman, 1993: Some statistical and dynamical properties of turbulence in the oceanic pycnocline. J. Geophys. Res., 98, 22 665-22 679. 